\title{
EXILIO Y DESEXILIO: EXPERIENCIA DE UNA ANTROPOLOGÍA. MÉXICO-MADRID-BARCELONA
}

Claudi Esteva Fabregat El Colegio de Jalisco, México

\section{Una forma de memoria}

Este trabajo es la puesta por escrito, posteriormente ampliada, de una conferencia que pronuncié con ocasión de mi participación en unas jornadas sobre exilios y ciencias sociales gracias a la invitación que recibí del grupo ERAPI, jornadas que se desarrollaron en torno al concepto de los retos epistemológicos de las migraciones transnacionales. El presente texto es, pues, diferente al de la conferencia. Sin embargo, por ser este más preciso $-\mathrm{y}$, todo sea dicho, de tono menos académico-, sustituye aquellas palabras.

Por ser esta una memoria, cuya redacción se basa directamente en recuerdos y en experiencias personales, he suprimido la práctica totalidad de las menciones bibliográficas y otras referencias, entre ellas títulos en los que me incluyo y que forman parte de mi currículo personal ${ }^{1}$.

1 El text que reproduïm va ser publicat a la revista electrònica Scripta Nova. Es tracta de la versió revisada d'una conferencia que va dictar el Dr. Claudi Esteva Fabregat. A Scripta Nova s'inclou també, al final de 
Es cierto que cuando a uno le encargan dictar, como en este caso, una conferencia sobre la posible influencia del exilio en la creación de organizaciones académicas, es harto difícil pasar por alto el condicionante de las relaciones sociales. Estas anteceden al origen de cualquier institución de docencia y enseñanza, pues en el proceso previo a su creación -en especial sobre una disciplina tan amplia y específica como la antropología- intervienen individuos y otros organismos que, inevitablemente, conllevan intereses ideológicos. Tales intereses aparecen en ocasiones como estorbos, como estímulos en otros y como medios de realización positiva en la finalización práctica del proyecto.

Desde esta perspectiva, lo que he escrito, sin merma de que en el futuro escriba más sobre el asunto, es el resultado de entrecruzar recuerdos en la intimidad pública - por paradójico que parezca- de amigos y contertulios, con quienes compartí aquella conferencia, con una reflexión somera respecto a la relativa abundancia de texto que he producido en comparación con lo que dije en aquella ocasión.

Los detalles de mis vivencias en el ámbito de la antropología en México, Madrid y Barcelona pueden servir a quienes gusten de conocer los pormenores de un proceso que dio origen a una forma de antropología que empecé a estudiar en otro país, en México. Es con el deseo de ponerlo por escrito que acudo a publicar estas líneas.

\section{Experiencias}

Después de la Guerra Civil (1936-1939), el destino del grueso de los republicanos españoles que pasaron a Francia fue el de los campos de concentración. Por mi parte, estuve cien días en uno de ellos, el de Saint Cyprien, en el sudeste francés. Embarqué como exiliado político en el vapor Sinaia el 23 de mayo de 1939 y llegué al puerto de Veracruz el 13 de junio. A diferencia de una Francia que nos había recibido con reparo y suspicacia, miles de mexicanos, que daban muestra de un ideal de solidaridad, nos

\footnotetext{
l'article, el debat que es va suscitar després de l'esmentada conferència. Seguint l'enllaç següent es pot accedir al debat: <http://revistes.ub.edu/index.php/ScriptaNova/article/view/1598>.

Referència de l'article: Scripta Nova. Revista Electrónica de Geografia y Ciencias Sociales, vol. XIII, núm. 291, 25 de mayo de 2009.
} 
recibieron muy afectuosamente a quienes viajamos en dicho buque. Tres días después llegué a la Ciudad de México en tren, donde nos dirigieron, junto con otros cinco compañeros, a un albergue de una institución, el Servicio Español a los Refugiados Españoles, dependiente del Gobierno de la República Española, por entonces establecido en la Ciudad de México.

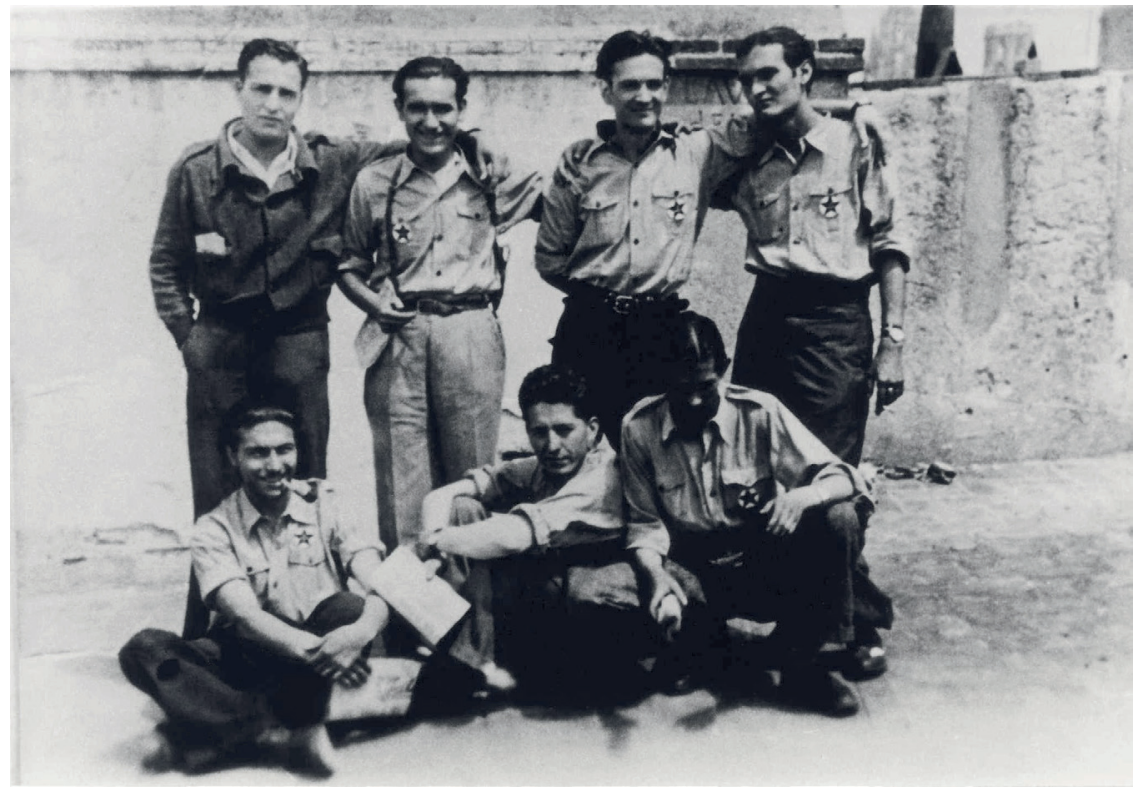

El Comitè de Barcelona de la JSUC, Claudi Esteva Fabregat (Secretari d' Organització) és el primer dret a l'esquerra, assegut al centre, Gregorio López Raimundo. Barcelona 1937 (c) Berta Alcañiz.

En aquel momento, el general Lázaro Cárdenas era presidente de la república mexicana y todos los refugiados españoles que llegamos a México por entonces recibíamos con devoción casi religiosa la imagen del que era uno de los estadistas más emblemáticos de la historia mexicana. Ya en la Ciudad de México, nos pusimos en contacto con nuestras organizaciones políticas; en especial, como catalanes, lo hicimos con el Orfeó Català, institución que, por su simpatía hacia nuestra causa, abrió sus puertas muy generosamente a todos los paisanos catalanes (y a otros que no lo eran). 
En Europa no solamente estaba extendiéndose el fascismo en las diferentes comunidades nacionales, sino que gran parte de la clase media de todos los países europeos se estaba adhiriendo a causas conservadoras y a otras que se oponían al avance del comunismo. En cuanto llegamos a México, cada uno de nosotros se vinculó, en función de su origen, a un centro regional. Nunca había presenciado la intensa actividad y variedad de los centros regionales: la Casa Regional Valenciana, el Centro Regional Murciano, el Orfeó Català, el Centro Andaluz, el Centro Gallego, el Centro Vasco, la Casa de Extremadura, el Centro Asturiano; uno de ellos era franquista, el Casino Español, al igual, si mal no recuerdo, que el Círculo Vasco Español.

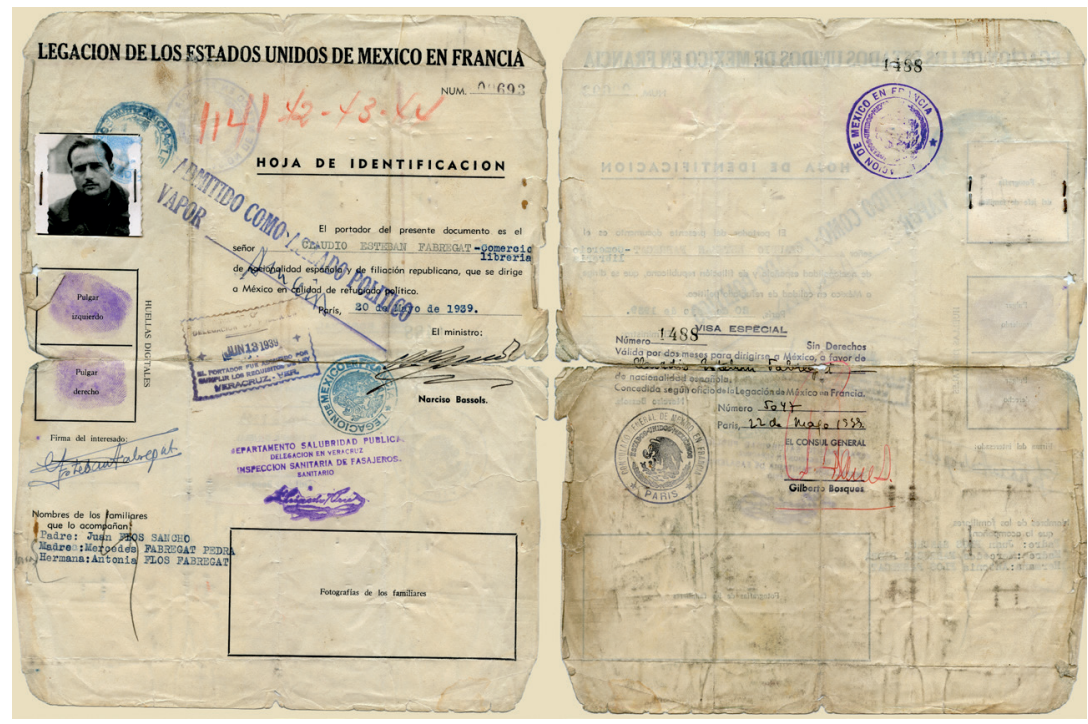

Document d'admissió d'exiliat polític de Claudi Esteva Fabregat a Mèxic, Legació dels Estats Units de Mèxic a França. Paris, 20 de maig de 1939 @ Berta Alcañiz.

En esta coyuntura, cuando llegué a México junto con otros compañeros que me acompañaban tanto de Barcelona como del campo de concentración, nos fuimos al Orfeó Català de México, lugar donde esperábamos encontrar una cálida acogida, como efectivamente y de manera generosa se nos dio. El lugar de encuentro que representaba la institución nos facilitó los encuentros con otros catalanes, con quienes podíamos conversar 
sobre nuestras vivencias en España y en el campo de concentración; lugar de encuentro donde también se podía leer la prensa. El Orfeó era, en definitiva, un referente de la vida social.

La Ciudad de México nos impresionó enormemente por varios motivos: la amabilidad de su gente, la belleza de su centro histórico y las modernas colonias que se estaban construyendo. En general, tuvimos buena y mala prensa. La buena procedía de los sectores gubernamentales, mientras que la contraria consistía en una versión que afirmaba que los refugiados españoles éramos sin excepción sospechosos de criminalidad diversa, comunistas represores del catolicismo, lo que propició algunas hostilidades contra nosotros. En mi recuerdo de los primeros días, aún conservo la imagen de que nos observaban con curiosidad y que, por nuestro modo de actuar, los mexicanos nos identificaban fácilmente como refugiados recién llegados.

Aunque el Gobierno de México contaba con el apoyo de sindicatos y la fuerza que le proporcionaba el entramado territorial de su organización política nacional, la oposición era notoria. La representaban las jerarquías eclesiásticas y los grupos de poder económicos tradicionales que comulgaban con el legado ideológico remanente del porfiriato, esto es, el régimen dictatorial implantado por el que fue presidente de la República hasta la Revolución de 1910, el general Porfirio Díaz. Habitualmente, las clases medias, por lo común vinculadas al catolicismo, eran las más propensas a sentir cierta hostilidad contra los refugiados a resultas de la propaganda del franquismo.

Por entonces, la oposición al Gobierno mexicano era muy diversa y algunos generales descontentos albergaban resentimientos contra el régimen político gobernante. Sus dialécticas se manifestaban en forma de levantamientos dispersos en algunas partes del territorio de la República, como el del estado de Nuevo León. El Gobierno seguía sofocando algunos de ellos y, si bien ejercía el control sobre el conjunto de los mexicanos, estas situaciones requerían de gran vigilancia política y producían inquietudes en los ambientes comprometidos. En cierto modo, la sospecha de que algo se estaba tramando por parte de los enemigos del Gobierno se había generalizado en algunas tertulias políticas muy expuestas a todo 
tipo de rumores. En este sentido, recuerdo perfectamente que una noche nos vino a ver en la cantina del Orfeó, lugar donde era frecuente ir a conversar un rato, un cliente, policía mexicano, quien nos contó que se temía un levantamiento de carácter militar, por lo que sería una buena opción que ayudáramos a combatirlo uniéndonos a una fuerza sindical armada que se concentraría en la Casa del Agrarista. Era, pues, tiempo de rumores permanentes de este tipo que ponían de manifiesto el temor de una insurgencia armada que pusiera fin a la continuidad de la Revolución mexicana. Así las cosas, junto con otros compañeros, acudimos a la Casa del Agrarista, donde nos dieron un fusil, a todas luces anticuado. Si mal no recuerdo, estuvimos dos noches y las pasamos con mucha ansiedad, pues las noticias que nos proporcionaban quienes estaban allí con nosotros eran pesimistas. El ambiente era tenso, pero me impresionaron los mexicanos por su actitud sobria y disposición firme; no dudaban en enfrentarse a un enemigo que, por rechazar la Revolución, parecía que los alentaba a combatir en nombre de un ideal amenazado.

¿Qué era México entonces? Puedo dar una respuesta en sentido general. México era un país que había entrado en guerra contra el eje fascista, que tenía una gran cantidad de refugiados de diversas partes de Europa. Había muchos alemanes, judíos alemanes, había algunos franceses que ya por entonces se estaban organizando como movimiento gaullista de liberación. Asimismo, había una gran cantidad de gente venida del centro de Europa y, desde luego, el grupo español, representado por unos cuarenta mil exiliados que, de muchas maneras, teníamos contactos entre nosotros y estábamos esperanzados con la idea de que, tarde o temprano, volveríamos a España para combatir de nuevo, para reconquistar la República que habíamos perdido.

Era un México, al igual que ahora, progresista, abierto, donde la diversidad marcaba el carácter fundamental de la sociedad mexicana.

Había, como ahora, sesenta y dos grupos indígenas, colonias extranjeras, como se los llama allí. En aquel momento el país vivía un importante progreso industrial gracias a su alianza con Estados Unidos, Francia, Inglaterra y la URSS, puesto que las industrias de algunos de estos países estaban dirigidas fundamentalmente a la producción industrial de arte- 
factos de guerra. México era el país que, junto con otros del mismo continente, proporcionaba a los aliados ropas, víveres y toda clase de recursos materiales, que ellos mismos no podían abastecer por no disponer de suficiente fuerza de trabajo. México aprovechó aquel ínterin, entre 1939 y 1945, para iniciar su industrialización. Era un país de marcado carácter rural y provinciano, y que poco a poco se iba integrando en un tipo de sociedad más urbana, con el objetivo de poder competir de algún modo en el mercado de la cultura internacional.

Quien vivía en la Ciudad de México por entonces podía estar al día de los grandes movimientos intelectuales. Trotsky acababa de llegar a México y las corrientes del marxismo revolucionario estaban ganando adeptos. Al mismo tiempo, había intelectuales de diferentes partes del mundo, de Europa sobre todo, y quienes venían de otros lugares de Hispanoamérica donde se habían instalado dictaduras a semejanza de la española; estos intelectuales, de algún modo, reforzaban el carácter cosmopolita de la Ciudad de México. La capital mexicana era por entonces el receptáculo de lo que podríamos llamar la combustión intelectual exiliada más moderna del momento.

El esfuerzo nacional por admitir refugiados fue considerable y los que hemos vivido aquel periodo calculamos que las personas que se habían refugiado en México huyendo de la represión en sus respectivos países llegaban, probablemente, a unas cien mil.

En nuestro caso, el de los más jóvenes que por entonces llegamos - tenía veinte años-, no encontramos grandes dificultades para integrarnos con la población y su idiosincrasia. No sufrimos grandes problemas de interacción cultural porque llegábamos solteros y, de algún modo, podíamos y queríamos involucrarnos por todo el sistema de la sociedad mexicana. En cambio, los que llegaban con más edad y casados debían cumplir con obligaciones de carácter económico, lo que los obligaba a buscar, de algún modo, remedio inmediato a sus necesidades materiales.

Muchos de nosotros, los más jóvenes, nos diseminamos por la república mexicana por diferentes motivos. En mi caso tuvo que ver con que yo había sido futbolista y conocía este deporte. Había jugado en el juvenil del Barcelona y, por esta razón, mis amigos me animaron a que jugara 
en la categoría profesional tras haberlo hecho en México en el club Catalonia, cuya sede social era el Orfeó. Esta experiencia sirvió para que me contrataran como profesional en un club de Puebla, el O'Farrill, por lo que fui a dicha ciudad a jugar al fútbol. Así, durante algún tiempo fui jugador de este deporte en Puebla. Allí se reunió un grupo de refugiados catalanes, entre los que me encontraba y a los que recuerdo con mucho afecto. En particular, guardo vívidas imágenes de Bota, que era de Gerona, así como de Soler Vidal, un compañero mío que era de Gavà (en realidad había nacido en el barrio de Sant Martí de Barcelona), entre otros más que nos reuníamos y que, de algún modo, representábamos en Puebla el exilio español en la ciudad. Manteníamos una comunicación constante, participábamos de la ansiedad general que provocaban algunas derrotas militares, quizá la más importante, la de Francia ante Alemania. También eran motivo de ansiedad tanto la retirada de los británicos en Dunkerque como los avances alemanes en la URSS.

En 1945 regresé a la Ciudad de México, tras haber pasado toda la primera mitad de la guerra mundial con cierta angustia. Durante el conflicto, la ansiedad se había generalizado hasta el límite de que no descartábamos la idea de que pudiéramos perder la guerra. Por lo tanto, nos preparamos también para contestar, en el mismo México, a los probables enemigos identificados con el nazismo, que destacaban por su agresividad política y por el anuncio de que pronto triunfarían, como resultado de sus avances, en Europa. La angustia no nos abandonó durante el tiempo que duró la guerra mundial. Sin embargo, había un factor que todos nosotros considerábamos favorable: el hecho de que el mundo democrático tendría que defenderse también en América, no solo en Europa, si los aliados perdieran la guerra. En ese sentido, recuerdo que los jóvenes hacíamos reuniones en las que se discutían cuestiones ideológicas, programas de planificación, en esencia, guiados por lecturas utópicas. También estas reuniones servían para revisar con espíritu crítico la guerra civil española.

Publicábamos entonces una revista que se llamaba Presencia y en la que incluimos la participación tanto de mexicanos, básicamente jóvenes y también estudiantes, como de exiliados de otros países de todas partes 
de América (Perú, Haití, diversos lugares de Centroamérica...) venidos a México puesto que estaban siendo perseguidos en sus respectivos lugares. Se nos unían para consolidar una idea, la del revolucionarismo, que, en el caso de México, estaba en consonancia con la ideología del Partido de la Revolución Mexicana, que entonces ejercía el poder.

Así las cosas, las líneas precedentes dan una idea del complejo ambiente político, hasta cierto punto muy dialéctico, que se vivía a nuestra llegada (1939). Aunque el Gobierno demostraba tener el control de la situación, había constancia de que la presión conservadora no se limitaba a protestar por la vía de la crítica y del rumor. Por el contrario, parecía apoyar la idea de desacreditar a las instituciones revolucionarias como forma de socavar la confianza política que los sindicatos, que apoyaban al Partido de la Revolución Mexicana, tenían en el Gobierno. Por otra parte, este último contaba con una gran capacidad de movilización ciudadana cada vez que el régimen se manifestaba en contra de las amenazas por parte de alguna fuerza adversaria.

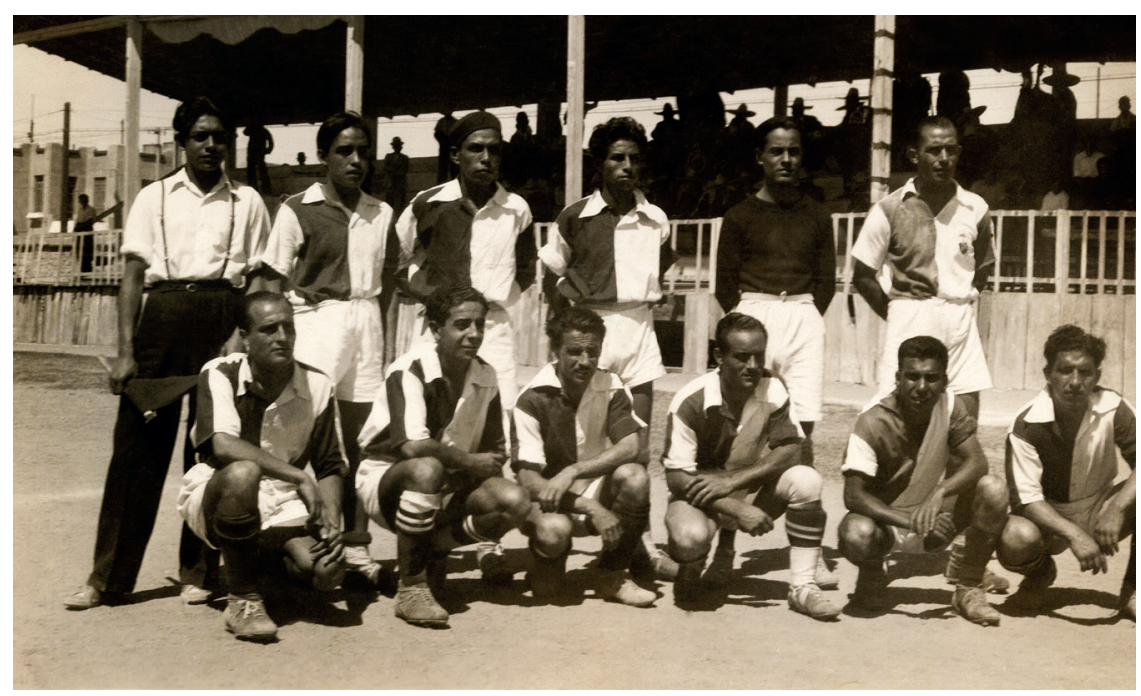

Equip de futbol O’Farril, Claudi Esteva Fabregat és el primer que esta a l'agetzoneta a l'esquerra. Puebla, Mèxic 1945 - (c) Gregorio Patiño @ Berta Alcañiz. 
De manera general, esta situación coincidió con el inicio de la Segunda Guerra Mundial, ante lo que México se comprometió con las naciones aliadas, que combatían al fascismo. Debido a los avances en el este de Europa y a las expansiones en el norte de África, también es cierto que el seguimiento de los primeros triunfos arrolladores de Alemania e Italia había generado un ambiente de nerviosismo entre los exiliados, sobre todo porque los grupos partidarios del eje en México estaban creciendo en términos de atrevimiento político y en capacidad de maniobra militante. Los grupos de españoles afectos al franquismo, que eran partidarios del triunfo del eje, solían amenazarnos con la devolución a España para que nos juzgaran allí. El conflicto entre los residentes españoles, llamados gachupines por los mexicanos, que ya se encontraban en México antes del conflicto español, era permanente y, entre aquellos, los partidarios de la República constituían una minoría. Así, el ambiente del grupo de los españoles migrados era, a grandes rasgos, una especie prolongación de la guerra civil española.

Esta situación se unía al ambiente crispado del exilio español ante muchas de las actuaciones políticas de sus organizaciones en México. Prácticamente, todas ellas sufrían procesos de expulsión de militantes discrepantes, todas ellas reorganizaban sus cuadros mientras muchos de los que habían formado parte de ellas abandonaban la militancia y se centraban en el presente y futuro de su vida, definitivamente en México.

Todo lo apuntado tenía lugar durante un periodo de la vida económica mexicana de marcado auge industrial, como ya apuntábamos líneas atrás, en expansión debido a que México era una retaguardia segura de las naciones en lucha contra el fascismo. Las fábricas textiles, por ejemplo, tenían tres turnos diarios y sus excedentes se exportaban a Estados Unidos. Toda producción se vendía, por lo que el esfuerzo de México se dirigió entonces a desarrollar una industria pesada y así proveerse de cierto desarrollo básico. Se trató históricamente de una época decisiva por cuanto se impulsó el crecimiento de su autonomía económica.

Obviamente, este crecimiento no solo produjo un mayor desarrollo económico, sino también un profundo cambio en los entornos urbanos, muy visible en la Ciudad de México, que se fue transformando paulatina- 
mente en una gran metrópoli y refugio de exiliados de todas las partes del mundo, especialmente de Europa e Iberoamérica. Gracias al auge económico y a la difusión de la ideología democrática, empezó a desaparecer la inestabilidad política y, al final de la contienda mundial, el país había alcanzado un alto grado de madurez. El final del conflicto mundial se produjo en un momento en que los exiliados eran mucho menos numerosos, pues algunos habían fallecido y otros habían adoptado la nacionalidad mexicana, y las organizaciones políticas se estaban desmoralizando a causa de que las instituciones y los dirigentes de la República española habían perdido la fe tras ser testigos de las políticas de los vencedores. Para entonces, los altos mandos republicanos ya no estaban preparando el regreso de los exiliados a España y gran parte del peso de la resistencia antifranquista se había desplazado al interior de las fronteras españolas. El miedo a los avances del comunismo en Europa sirvió de apuntalamiento del régimen franquista, por lo que, ante esta circunstancia, las organizaciones republicanas en el exilio comenzaron a perder fuerza y convicción; así, los exiliados dejamos de ser miembros activos de la política y nos convertimos en miembros activos de la sociedad mexicana.

\section{Estudiar Antropología}

En el ambiente que he descrito, dos años después del final de la Segunda Guerra Mundial, un buen día (nunca mejor dicho), iba yo por una calle de Ciudad de México, cercana al Zócalo, cuando vi un cartel de grandes dimensiones en el que se leía: «Escuela Nacional de Antropología e Historia. Iniciación de curso». Entonces, entré en la escuela, pregunté por el secretario y, tras recibirme (muy bien, por cierto), le pedí que me explicara el programa que ellos habían elaborado. Me lo contó todo y me animó a ingresar en el centro. Fue entonces que inicié el primer curso en la Escuela de Antropología.

Para mí representaba una experiencia de enorme importancia, porque la Escuela Nacional de Antropología e Historia de México (ENAH) era una institución que se había fundado bajo el espíritu de la Revolución mexicana. De hecho, los políticos dirigentes implicados en la Revolución mexicana habían llegado a la conclusión de que la antropología podía ser- 
vir para que la sociedad mexicana asimilara a los indígenas de sus territorios, que se agrupaban en sesenta y dos comunidades. Por entonces, estos grupos estaban aislados en cierto sentido: vivían en comunidades autosuficientes y hablaban lenguas diferentes al español. Por lo tanto, se pensaba que era conveniente apoyar cualquier esfuerzo que se hiciera en México para incorporar a los indígenas al resto de la sociedad nacional mexicana. Se habían hecho esfuerzos por medios políticos, pero el Gobierno se había mostrado ineficaz a este respecto. En aquel momento se sentía la necesidad de integrar a estos grupos para que fueran mexicanos en conciencia y en aptitud política, pero, sobre todas las cosas, en cultura.

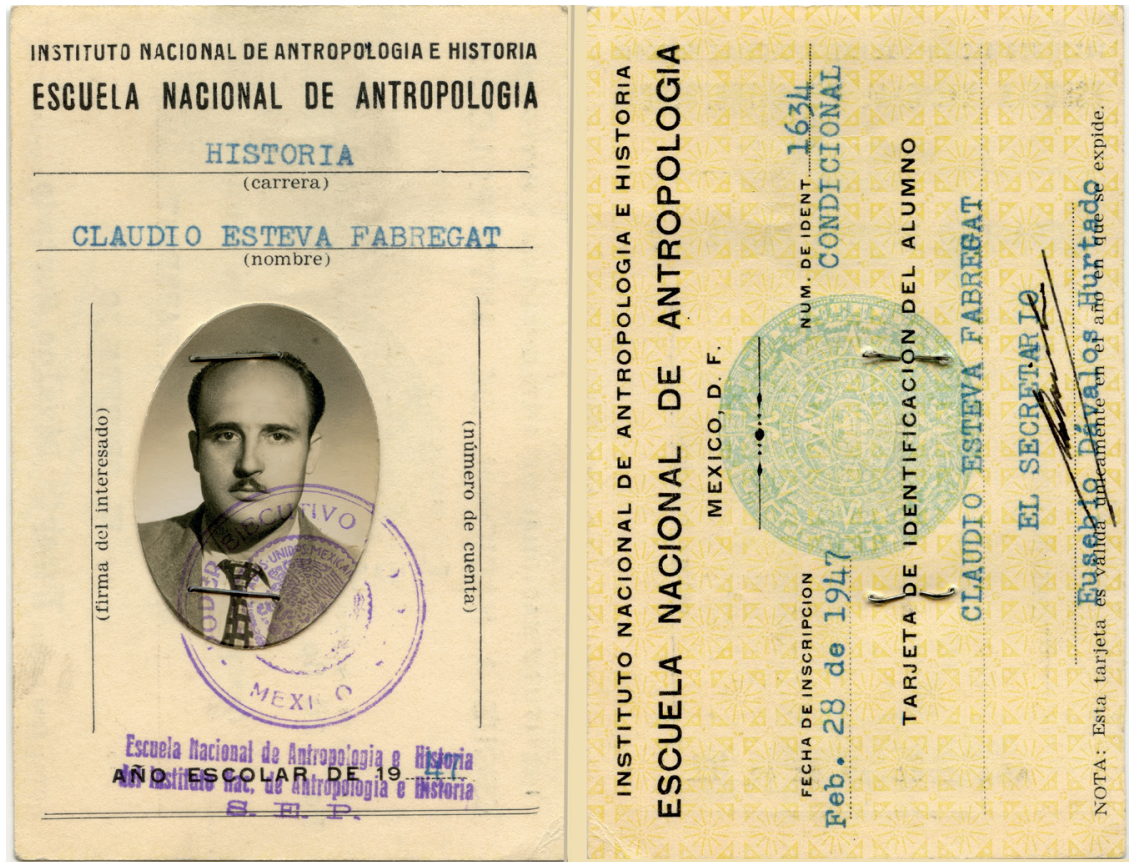

Credencial d'estudiant de Claudi Esteva Fabregat a l'Escuela Nacional de Antropologia e Historia (ENAH). Mèxic 1947. (c) Berta Alcañiz

El enfoque del Gobierno mexicano en el terreno de la antropología guardaba un estrecho vínculo con el pionero en este ámbito en tierras mexicanas. Un antropólogo estadounidense de origen alemán y judío, Franz Boas, había estado en México — si no recuerdo mal- hacia el año 
1925. Había estado trabajando con Manuel Gamio, con quien también había estudiado Antropología en la Universidad de Columbia, Estados Unidos. Igualmente, Manuel Gamio había participado en reuniones con Franz Boas y lo había convencido para que fuera a México y allí procurara orientar la antropología para que fuera capaz de enfocar el problema de las culturas indígenas desde la perspectiva integral de la antropología que se realizaba en el país norteamericano.

Manuel Gamio fue uno de los primeros antropólogos formados en Estados Unidos que había intentado estudiar la cuestión indígena de un modo integral. A partir de esa experiencia, y por cuanto era militante de la Revolución mexicana, convenció al presidente en aquel momento para que se fundara una escuela de antropología en México cuya principal ocupación sería estudiar a los grupos indígenas. Muchos de estos detalles se conocen gracias al libro que escribió Gamio sobre su experiencia como antropólogo en México, obra que redactó tras haber invitado a Franz Boas al país.

El programa de la ENAH en aquel momento era muy atractivo ya que ponía el foco en una antropología aplicada, de marcado carácter práctico. Por lo tanto, los que estudiábamos en la ENAH empezamos a preocuparnos inmediatamente por temas mexicanos. Me atrevería a decir que, quizá, una de las tareas más importantes de la escuela fue la de mexicanizarnos; es decir, la escuela, en principio, no se ocupaba de estudiar la antropología europea o estadounidense, sino que estudiaba al pueblo mexicano en su diversidad. Es por lo que, desde esa perspectiva, las analogías que en aquel entonces se pudieran establecer con respecto a fenómenos externos al país fracasaban totalmente. Los estudios de Antropología que se habían establecido en México estaban totalmente desvinculados de la idea del colonialismo; más bien se trataba de enfocar la disciplina a la liberación política de los pueblos indígenas mediante procesos de cambio cultural. Esta idea era muy atractiva porque representaba un horizonte en el que nos sentíamos reflejados todos los que, de alguna manera, habíamos sido expulsados de nuestros países y veíamos un claro paralelismo con respecto a nuestros lugares de origen, del que nos habíamos visto obligados a huir. 
Así que, de un modo parecido a un esencialismo cultural, lo que se vivía con respecto a la antropología era un indigenismo irredentista. A tenor de esto, la reflexión necesaria era que conocer etnográficamente a los indígenas equivalía a comprenderlos mejor y en el propósito de mexicanizarlos residía, mediante el conocimiento antropológico, la voluntad de ayudarlos a vivir mejor. Se pretendía, a través de la aplicación de una correcta forma de hacer antropología de campo, provocar que los indígenas tomaran conciencia de la mexicanidad. Así las cosas, el conocimiento etnográfico constituía la base sobre la que establecer una buena política nacional, gracias a los indigenistas.

Esta percepción del problema indígena y su dimensión antropológica me llevaba a una convicción: los estudios antropológicos desempeñan un papel político indiscutible cuando la descripción etnográfica está bien construida. Cada vez estaba más persuadido de esta idea, a medida que profundizaba en esta clase de problemas. De modo que, a medida que reflexionaba sobre un posible papel de la antropología en España, tomaba más conciencia de que todo saber sobre la cultura de una nación o de una identidad étnica debía tener un carácter prescriptivo, esto es, debía ser una condición previa e ineludible para aplicar una política específica.

La cuestión, no cabe duda, tenía un carácter ético que se hacía patente por la desigual situación de partida de las dos partes, la observadora y la observada. Saber, por ejemplo, cómo eran los mexicanos -igual que en cualquier otra parte del mundo- era condición necesaria para que los políticos que dirigían el país pusieran en marcha medidas sobre la base de un conocimiento indispensable. Obviamente, la antropología construye este conocimiento y lo hace, más precisamente, a través de la etnografía.

El objetivo primordial de los estudios indigenistas en la ENAH era conocer científicamente a los grupos y comunidades indígenas. Transmitir este conocimiento era también un modo de reflexionar acerca de las relaciones interétnicas, pero también se podía aplicar a las relaciones entre los Estados. En definitiva, se trataba de conocer la dialéctica que construye la política en una relación etnográfica cuando se desconoce en gran medida al interlocutor. 
En aquel momento, la escuela tenía un gran número de profesores europeos. Habían venido de Noruega, Suecia, Reino Unido, Alemania, Francia y, especialmente, de España. Y, además, había un grupo de profesores de Estados Unidos que se hicieron famosos y que también nos enseñaban antropología. Por otro lado, estaba el núcleo principal de mexicanos, cada uno proveniente de una disciplina diferente: geología, geografía física, filosofía, historia, entre otros ámbitos; estos nos enseñaban sobre ciencias naturales. En este sentido, cabe destacar que me inscribí en una escuela de antropología fundada en los principios de las ciencias naturales, es decir, al igual que en estas, el conocimiento se basaba en el método empírico. Todo aquello que no pudiera demostrarse empíricamente se convertía en una hipótesis de trabajo, pero no en una realidad suficientemente convincente. De manera que nos formaron desde el comienzo en la idea de que la antropología era una ciencia natural y, por ello, de corte empírico. La etnografía era el punto a partir del cual se podía diferenciar la antropología de otras disciplinas como las ciencias históricas o las llamadas ciencias sociales. Aunque no voy a entrar en detalles - pues podría resultar en una larga disquisición-, en lugar de ciencias sociales (al fin y al cabo, todos los grupos animales son sociales), deberíamos llamarlas ciencias culturales, pues precisamente lo que nos distingue de los demás animales es el hecho de ser culturales.

En resumen, y como ya he apuntado, estudiábamos en un medio docente dominado por el papel de las ciencias naturales. Nos enseñaban sobre geología, anatomía, antropometría, paleontología, arqueología, lingüística, historia... Asimismo, estudiamos la etnografía de muy diversos lugares y, luego, nos ocupábamos de teorías, de enfoques diversos, de inducción y deducción, de aculturación o de las consecuencias de las mediaciones culturales marcadas por el difusionismo. Los indígenas y el mundo prehispánico eran los escenarios donde poníamos a prueba las teorías antropológicas que construíamos sobre la base de las realidades comparadas. De este modo, completábamos la imagen de un mundo etnográficamente diverso y nacionalmente plural, con diferentes realidades regionales. Y el enfoque boasiano constituía un entrenamiento antropológico, con el objetivo de construir una mirada empírica puesta en 
práctica con la realidad de los sujetos sometidos a estudio. Se trataba del enfoque de los departamentos de Antropología de Estados Unidos, que habían incorporado las cuatro ramas.

Mi propio nombramiento como profesor de la ENAH tuvo lugar en virtud a la creación en aquel momento de una línea de antropología social. Había recibido formación en esta área gracias a los cursos de la ENAH, así como a quienes vinieron, especialmente de la Escuela de Chicago, a instruirnos a tal propósito, como el brillante Robert Redfield, autor de estudios sobre Yucatán y Tepoztlán. También cabe destacar la influencia que recibimos de Bronisław Malinowski, quien realizó una corta pero fructífera visita a México. Ambos, Redfield y Malinowski, dejaron una importante huella en algunos de los profesores de la escuela, como Alfonso Villas Rojas, Julio de la Fuente, Fernando Cámara y Arturo Monzón. Gracias a esta formación y a que se me ofreció la oportunidad, pude enseñar por primera vez Antropología Social en la Escuela de Graduados de la Facultad de Psiquiatría de la Universidad Nacional Autónoma de México (UNAM). Obviamente, los contenidos de la materia incluían cuestiones relacionadas con las enfermedades del mundo psíquico desde la perspectiva de las manifestaciones culturales. Se trataba de una metodología comparada y se proponía estudiar los cuadros clínicos de diferentes poblaciones sobre las que se disponía de materiales concretos de campo. Curiosamente, comencé a impartir la asignatura en la Facultad de Psiquiatría porque me había incorporado al programa psicoanalítico mexicano puesto en práctica tras la llegada de Erich Fromm a México. Entonces me nombraron secretario del seminario de psicoanálisis y, como fruto de mi relación personal con Erich Fromm, se me invitó a que impartiera Antropología Social en la Facultad de Psiquiatría. Posteriormente, en la ENAH también me pidieron que hiciera lo propio, pero con contenidos más ligados a los del curso de Cultura y Personalidad; mi formación en psicoanálisis resultaba muy valiosa, en especial en lo que a la cultura - sus implicaciones y referentes- en las relaciones sociales respectaba. Sin embargo, el enfoque de mi trabajo en antropología social distaba del adoptado por el reputado antropólogo A. R. Radcliffe-Brown. La diferencia consistía en el hecho de que, a diferencia de este último, que trabajaba con material de sociedades 
primitivistas, en mi caso estudiaba la vida mexicana rural y urbana que se construía en torno a los actos sociales vinculados con una realidad cultural específica; por ejemplo, la de los obreros industriales en la Ciudad de México. Así, los textos etnográficos sobre los pueblos primitivos servían básicamente para compararlos con los del entorno urbano y mis colegas y yo comenzábamos a producir textos sobre este último ámbito cultural. Se trataba de estudiar estas cuestiones aplicadas al mundo urbano y con un enfoque investigador empírico pretendíamos llegar a conclusiones sobre los comportamientos institucionalizados. La psiquiatría mexicana, al igual que las áreas de investigación que la ENAH abarcaba, el empirismo dominaba y trabajaba con los recursos del trabajo de campo que aportaba la antropología.

La ENAH era muy receptiva a cualquier tipo de innovación. Por ejemplo, en ella había un grupo marxista muy activo que orientaba sus conclusiones a la idea de que los indígenas formaban una clase social. La discusión teórica era obvia. Había, asimismo, un grupo que podría calificarse de historicista y que explicaba todos los fenómenos mexicanos con relación a lo prehispánico. Por otra parte, estábamos, entre los que me incluyo, los que íbamos acumulando conocimientos, perspectivas e ideas que nos hacían pensar cada vez más que era conveniente incorporar una línea en la antropología mexicana que estaba ausente en aquel entonces: la línea psicoanalítica. Se hacía necesario un enfoque que estudiara, desde la perspectiva de la psicología, a los grupos humanos y su cultura, teniendo en cuenta que la personalidad se construye mediante un proceso de socialización definido durante la infancia.

Los dos cursos de Cultura y Personalidad que impartí incluían la descripción etnográfica de las poblaciones y ponían el acento en las categorías psicoanalíticas que explicaban las proyecciones adultas en función de las experiencias infantiles, cruciales en la formación de la estructura psíquica de los individuos que forman parte de la sociedad. Mi experiencia en psicoanálisis y la integración de los recursos teóricos de la antropología en este ámbito constituyó un importante avance porque incorporaba en 
los datos etnográficos el componente psicodinámico, más en términos de psicología social que de psicología individual.

Mis intereses, muy variados, me provocaron que adoptara una postura un tanto ecléctica. Cabe, por eso, subrayar que nunca he abandonado la idea de que el enfoque epistemológico es fundamental en todo intento de situar la antropología dentro de una determinada heurística del conocimiento. A este respecto, cuando en los planes de estudio de la ENAH se estaba contemplando la idea de situar la cultura como el centro estratégico de los estudios de Antropología para, a partir de ella, explicar la conducta humana en su estricta expresión social, se me ofreció una materia que nombramos Historia de la Cultura.

Por entonces se comenzaba a contemplar la influencia de la genética en diversos campos, por lo que era obvio para muchos de nosotros que la antropología física debía someterse más a los nuevos aportes de este campo de las ciencias naturales. Los nuevos descubrimientos nos permitirían acercarnos más a la realidad biológica de un proceso de construcción cultural sobre una base biológica. El punto esencial de estos nuevos conocimientos residía en determinar hasta dónde lo biológico condicionaba lo cultural. En cierto modo, en aquel momento y, probablemente, por una influencia considerable del racismo, las cuestiones relacionadas con el concepto de raza se estaban orientando a descubrir hasta qué punto la raza determinaba genealógicamente la construcción de la civilización. Por entonces, todo era hipotético, lo que no impedía que tanto profesores como discípulos, la mayoría de los casos adeptos a la corriente culturalista, contáramos con grandes dosis de motivación.

En este particular, se hace necesario reconocer que la ENAH contaba con un sello de identidad que le era propio, el de la innovación constante. Incluía en los tres cursos a los que he hecho mención contenidos específicos muy novedosos. Era la primera vez que se planteaba el psicologismo como método hermenéutico en la antropología tradicional, lo que, epistemológicamente, estrechaba la relación de la cultura con la formación de la estructura de la personalidad básica —en términos de Abram Kardiner-. Esto se hacía realidad, por ejemplo, en la enorme dificultad a la que nos enfrentábamos cuando se debía aplicar la explicación del 
carácter individual a la explicación del carácter colectivo. Por otra parte, en las ciencias naturales no era tradición explicar culturalmente las funciones sociales de la psique. Tampoco era frecuente hablar de historia de la cultura; sin embargo, en sentido evolutivo y en términos de difusión, el uso de estas categorías distinguía a los antropólogos de otros científicos, por lo menos en cuanto al historicismo que ofrecían los enfoques del evolucionismo y el difusionismo, visión muy conocida durante el auge historicista de las primeras discusiones. Con todo, como antropólogo me reconocía, además, en diferentes facetas: la de historiador en los estudios sobre el mundo prehispánico; la de funcionalista en la investigación que conducía desde la antropología social; y la de culturalista en las repercusiones del psiquismo en la construcción cultural.

$$
* * *
$$

Para impartir Historia de la Cultura tuve muy presentes dos ideas: usaría un planteamiento estrictamente evolutivo, pero divergente, al tiempo que me centraría en el difusionismo para explicar fenómenos de relación histórica entre las sociedades. La variedad de orientaciones que ofrecen los enfoques mencionados implican tomar en consideración el eclecticismo para poder interpretar correctamente los datos de campo. Esto implica que la variedad de los resultados puede representar diferentes verdades, es decir, un mismo dato puede ser relevante en el ámbito de la historia si mi interés es histórico, mientras que puede ser funcional si lo interpreto de forma sincrónica. En resumen, toda manifestación de interés etnográfico se puede tomar como un conjunto sometido a evolución histórica, pero muchos de sus elementos, también, constituyen circuitos de interacción inalterables con el tiempo.

Ante esta situación, lo que yo, ecléctico en mis intereses, defendía en aquel momento era una especie de praxis plural, esto es, contaba con una gran amplitud de miras a la hora de tomar los elementos que consideraba válidos y someterlos a análisis desde muy diferentes ámbitos, todo ello con el fin de explicar unas manifestaciones culturales en concreto. Desde luego, la idea de que en esta amplia gama de campos del saber formaban parte las ciencias naturales me agradaba muchísimo. Por ello cursé 
las cuatro ramas, de manera que, a pesar de que la formación conllevaba la especialización en un determinado ámbito, en especial en la etapa investigadora, no perdí de vista el hecho de que algunas explicaciones implicaban el conocimiento de diversos campos del saber. Recuerdo a este respecto que cuando estudiaba Geología, el profesor de esta materia nos llevó a estudiar unos estratos geológicos en el valle de México. Los estratos, diferentes entre sí, eran un reflejo variado de diversas formas del medio, flora y fauna incluidas. Al preguntar sobre tales diferencias, el profesor, geólogo de formación, nos respondía que la diversidad se explicaba por las condiciones de temperatura, fauna y flora, que variaban con el tiempo, lo que se reflejaba en los estratos. El profesor añadió la explicación de la leyenda de los soles y la relación que guardaba con los estratos que estábamos estudiando. La leyenda de los soles es muy conocida en México. La compartían los grupos prehispánicos y explicaban cómo se forjaron las edades del hombre y las delimitaban con hechos históricos, de manera similar a nuestras edades en Occidente. Lo que hacía el profesor Manuel Maldonado al enseñarnos a distinguir los estratos era, por un lado, mostrarnos que los estratos geológicos podían decirnos qué había sucedido en el pasado mediante las evidencias de las especies vegetales y faunísticas, material propio de los arqueólogos; por otro, al afirmar que los estratos registraban la experiencia de los pueblos mexicanos (un estrato se relacionaba con un diluvio, otro con un gran terremoto, otro una gran actividad volcánica y otro una gran tormenta huracanada), se nos transmitía cómo era la noción clasificatoria del tiempo de los grupos indígenas de México. De hecho, según la leyenda, cada época estaba marcada por una catástrofe que se manifestaba geológicamente (en los estratos) e históricamente (en la leyenda); tras cada destrucción, cuenta la leyenda, el pueblo renacía. Según la misma leyenda, tras la invasión de los españoles, estamos viviendo la quinta edad, el quinto sol.

Así las cosas, los alumnos discutíamos hasta qué punto la creación de los criterios de medición del tiempo tenía que estar basada en factores cronológicos. Los pueblos prehispánicos apuntaban a que se hacían en función de los acontecimientos decisivos en lugares determinados, hechos que constituían, por otro lado, la mitología del sistema. Es precisa- 
mente por esto que mis compañeros de Antropología estaban de acuerdo conmigo cuando sosteníamos que la clasificación naturalista estaba registrando la experiencia de las edades según formas cronológicas diferentes a como la tradición occidental solía hacerlo. Se reforzaba mucho la idea de que estábamos ocupándonos de concebir la historia natural en términos de antropología.

Con respecto a las mencionadas cuatro ramas de la antropología, algunas investigaciones requerían la participación de todas ellas. Por ejemplo, recuerdo en una ocasión que teníamos que determinar si un alimento en concreto, encontrado mediante evidencias geológicas, beneficiaba o perjudicaba la salud de determinados grupos; ante la duda, íbamos a un laboratorio. Así, nos acostumbraron a ir a un laboratorio para comprobar qué contenidos incluían ciertos materiales orgánicos y, luego, con el diagnóstico, podíamos confirmar o refutar una teoría precoz que, hasta entonces, no se había verificado empíricamente. También recuerdo que gracias a otra evidencia en los estratos, esta vez relativa al consumo de maíz y de frijol, pudimos explicar la realidad alimentaria de unos grupos que, gracias a esta incorporación a su dieta, disfrutaban de una mayor longevidad que también se manifestaba en las evidencias arqueológicas de los enterramientos, que ya entonces, antes de las comprobaciones de laboratorio, nos llevaban a pensar en esta relación entre el consumo de alimentos y el alargamiento de la vida de los grupos.

\section{Una experiencia fundadora: Madrid}

Llegué a Madrid en junio de 1956. Me establecí en la capital española porque había recibido una invitación por parte del catedrático de Historia Prehispánica y Arqueología Americana de la Universidad de Madrid, Manuel Ballesteros Gaibrois, asimismo vicedirector del Instituto Gonzalo Fernández de Oviedo del Consejo Superior de Investigaciones Científicas (CSIC). Cuando llegué a Madrid traía conmigo dos cartas de presentación, una del profesor Juan Comas Camps para Manuel Ballesteros Gaibrois y otra del profesor Pedro Bosch Gimpera para Luis Pericot García. Ambas eran muy elogiosas para mi persona y, desde luego, recomendaban que me ofrecieran soporte académico, cosa que el profesor Balleste- 
ros hizo inmediatamente. Por parte del profesor Pericot, su apoyo vino, tras reticencias, unos años después, con ocasión del concurso-oposición a la agregaduría de Etnología. Luis Pericot era una persona muy temerosa y no solía apoyar lo que podía representar una opción política que lo comprometiera con el poder. Tras reflexionar, opté por la prescripción universitaria de Madrid, entonces institucionalmente más abierta a los temas de mi interés que la de Barcelona.

Debido a que la remuneración no era suficiente para mantenernos a mí y a mi familia en la capital, por entonces trabajé para la Organización Sindical Española en la realización de estudios sobre migración interior y exterior en España, así como sobre los problemas de los enlaces sindicales. La Cámara de Comercio de Madrid me encargó otros estudios sobre cuestiones relacionadas con el desarrollo del pequeño comercio de Madrid. El enfoque de estos trabajos era el propio de la encuesta sociológica. Al mismo tiempo, en el ámbito estrictamente antropológico, colaboraba mediante recensiones y comentarios sobre temas vinculados a los contenidos específicos de algunas publicaciones como la Revista de Indias, Arbor y la Revista Internacional de Sociología, todas ellas del CSIC. También publiqué en Cuadernos Hispanoamericanos y, especialmente y de forma periódica, en Índice de Artes y Letras, una publicación que reunía a grupos de intelectuales del exilio y del interior crítico e ideológico español, representado básicamente por las segundas generaciones universitarias, que se posicionaban en contra del régimen. Mientras tanto, mantuve mi colaboración, entre otras publicaciones de antropología, con la revista mexicana Horizontes, dirigida por el periodista y escritor exiliado catalán Pere Foix.

En aquel momento, la Universidad de Madrid fue la principal institución universitaria donde trabajé y colaboré. En ella, pocos meses después de mi llegada a Madrid, pronuncié conferencias e impartí cursos: Cultura y Personalidad (1956-1957), Cultura y Sociedad Azteca (1956-1957), Problemas de Antropología Cultural (1956-1957) o Antropología de Hispanoamérica (1956-1958). Además, en la Universidad Pontificia de Salamanca ofrecí uno sobre el Continuum Rural-Urbano (1959). Por su parte, en el Instituto Municipal de Educación de Barcelona, impartí un cursillo 
en forma de seminario sobre antropología social (1959)². Quizá un primer antecedente escrito en España de introducción epistemológica de esta y de otras materias por entonces propias de una entrada de novedades antropológicas en la Universidad española.

Con todo, y como ya adelanté líneas atrás, teniendo en cuenta que yo había trabajado especialmente en cuestiones relativas a la historia cultural prehispánica, la Universidad de Madrid era el lugar en el que podía integrarme de algún modo. En un primer momento, mis posibilidades de formar parte del el sistema universitario español eran muy escasas, pues debía convalidar mis estudios de México. Tuve, pues, que aprobar las materias de licenciatura y hacer después mi doctorado en dicha universidad, pues estos eran los requisitos para tomar parte en las oposiciones a plazas fijas de universidad. Me encargaron impartir varios cursos y me invitaron a dictar conferencias sobre asuntos de mi especialidad en diferentes lugares del país. Impartí asignaturas sobre la América prehispánica, las religiones indígenas y otras de antropología general. Por su parte, en materia de conferencias, abordé el mestizaje y la situación histórica de la etnología española en función de sus necesidades y desarrollo estratégicos.

En este ambiente, de docencia e investigación en instituciones públicas, mis relaciones profesionales me hacían transitar por la sociología y la antropología sociocultural. De hecho, el concepto de cultura era, quizá, el que empleaba con más soltura teórica en mis conferencias y cursos.

$$
* * *
$$

Los debates surgidos de mis ponencias fueron también la ocasión en que expresaba lo que pensaba por entonces sobre los problemas de enfoque de los estudios de la antropología peninsular. Desde luego, el planteamiento específico de una etnología peninsular tenía que ver con la idea de que una comprensión correcta de la cultura española debía conllevar el conocimiento previo de su diversidad étnica y de sus tradiciones culturales que habían dado lugar a los conceptos nacionales de identidad. Había

2 Ya había publicado un ensayo dos años antes sobre ese ámbito (Esteva, 1957). 
que tener en cuenta que las regiones que formaban parte del Estado español conformaban culturas etnográficamente diferenciadas, en especial - aunque no solo- por sus lenguas y variedades dialectales propias. Así, el castellano, el catalán, el gallego y el euskera ocupaban regiones propias delimitadas por sus expansiones territoriales y marcas lingüísticas. Sin embargo, estas particularidades no estaban suficientemente representadas en el ámbito político. Pensaba (y sigo pensando) que se debía partir de las comarcas para el estudio etnográfico de la Península; este tenía que ser el inicio del estudio que permitiría articular una noción de unidad etnográficamente articulada.

Cabe destacar, por otra parte, que este proyecto lo había conversado en el exilio, en México, con el profesor Pere Bosch-Gimpera, don Pedro, como se lo conocía por el respeto que a muchos nos inducía el trato con él. Fueron varias las ocasiones en que solía idear junto a él alguna que otra posible gran investigación de futuro. Sin duda, por aquel entonces la visión política que dábamos los jóvenes exiliados en México con respecto a nuestro país era la que resultaba del reconocimiento de estas diferenciaciones etnográficas. Recuerdo que en una de las tertulias que manteníamos sobre el estudio de la situación política del país, la idea de peninsularidad ibérica estaba presente en los debates que iniciábamos y en los que siempre estaba presente la diversidad etnográfica, entendida como referente de toda peculiaridad federal o confederal ibérica de cara a su organización estatal.

Así, mediante al citado proyecto, se pretendía determinar la historia de una peninsularidad etnográficamente diversificada a través de la demostración y análisis antropológicos. Sin embargo, la mera idea no la concebía la primera generación política del momento, no así, afortunadamente, entre quienes pertenecían a la segunda generación, quienes mostraron una actitud comprensiva respecto al proyecto antropológico. En este contexto, el proyecto quedó relegado desde el primer comentario que hice sobre el desarrollo y aplicación política posterior. Sin duda, uno de los grandes problemas de España, a mi juicio, era el desconocimiento de una realidad cultural distintiva según los territorios y que el proyecto etnográfico podría ayudar a solucionar, tanto mediante el co- 
nocimiento antropológico como a través de su aplicación política, esto es, con la formación de un Estado plurinacional, organizado de manera confederal, de forma parecida a la solución helvética.

Ante esta situación, a pesar de que el proyecto de una etnología peninsular fuera atractivo, su realización era impensable por parte de las instituciones oficiales de aquel tiempo. Hubo a la sazón un intento de convencer a una institución bancaria, el Banco Urquijo, que por entonces subvencionaba a algunos intelectuales disconformes con el sistema. Se logró una primera invitación cuyo principal objetivo era precisamente atender económicamente un proyecto de este tipo. En la única reunión que se convocó por parte del banco hubo desacuerdos conceptuales sobre la distribución de las áreas de trabajo. Además, también es cierto que las autoridades de la institución tomaron consciencia de los problemas que podrían emerger de las confrontaciones y de los avisos de peligrosidad política si se llevara a cabo el proyecto.

$$
* * *
$$

¿Cuál podía ser la influencia de una vida marcada por el exilio una vez que ya me encontraba en Madrid? Pienso que hubo principalmente tres factores: haber vivido en un México etnográficamente plural; el tipo de conceptos del ámbito de la antropología y las posturas que tomaba en mis actividades universitarias; y la toma de conciencia de que en la España de entonces emergía una generación diferente, de mayor apertura ideológica, que comenzaba a ocupar puestos académicos en la Universidad, lo que favorecía mi entrada en los claustros que allí tenían lugar.

Cabe destacar mi primera experiencia en un claustro universitario. Por aquel momento, solo los catedráticos tenían derecho de intervención y decisión. Así que entré en la sala donde tendría lugar el encuentro y me senté en una mesa grande, situada en el centro de la sala. Acto seguido, un compañero mío, encargado de curso, al igual que yo, me sugirió que abandonara cuanto antes el lugar que ocupaba porque estaba reservado solo para catedráticos. La rigidez de la estructura jerárquica estaba presente en la organización universitaria y las distinciones resultantes suponían exclusividad de privilegios por parte del estamento catedráti- 
co y la subordinación de adjuntos y encargados de curso, como era mi caso. Esto se hacía patente en la diferencia de trato formal, por lo que era habitual dirigirse a los catedráticos introduciendo don, mientras que estos utilizaban con los encargados de curso o adjuntos solo el apellido o el nombre tras usted o tú. Lo cierto es que era habitual cierto espíritu protector por parte de los catedráticos hacia los encargados o adjuntos. Se esperaba que en los ejercicios de oposiciones a puestos vitalicios cada catedrático hiciera lo posible para que los miembros del tribunal favorecieran la promoción de su propio adjunto o del encargado de curso que había promovido, en el caso de haber intervenido en su nombramiento.

Por mi parte, evitaba perpetuar esta situación, así que actuaba solo en función de la diferencia de edad como forma de estatus. En este sentido, la siguiente generación académica nacida en el país, más joven, presionaba para romper este distanciamiento en las formas de comunicación, pero se mantenía cierta inercia tanto en la comunicación verbal como en la escrita.

Por otra parte, en el ambiente universitario se admiraba a priori al profesor o investigador venido de instituciones extranjeras, en especial las del mundo anglosajón, aunque también gozaban de prestigio las germánicas y francesas. En cambio, el mundo iberoamericano formaba parte de otra tradición, históricamente más familiar. A los que llegábamos del exilio en calidad de académicos nos vinculaban a nuestros prestigiosos antecesores, las grandes figuras intelectuales de la llamada España peregrina, la de la época — superior en términos de pensamiento- de la República. Más allá de nombres concretos, se hacía patente una aureola que distinguía a los académicos de las universidades españolas de la República exiliada, lo que provocaba con frecuencia que en toda presentación pública que hacía se me asociara con alguna de las figuras refugiadas en México. Era común que se me preguntara por los académicos exiliados, que el sector crítico de la generación más joven acostumbraba a leer. Así, una minoría de los que enseñaban en España formaba parte de los admiradores de los maestros en el exilio.

Así que mi experiencia en el exilio determinó numerosas situaciones. De alguna manera formaba parte de mí, como si se tratara de un rasgo de 
personalidad y repercutía en una percepción positiva de la esfera política en el exilio. Si bien me era difícil ascender por los escalafones universitarios, no lo era, en cambio, recibir el apoyo de quienes viajaban fuera del país y que, sin hacer alarde de ello, se mostraban como liberales afectos a la renovación política y a la modernización de la vida académica. En cierto modo, lo que yo pensara no era tan importante en sí mismo como la circunstancia de venir de fuera. Así pues, lo que podía ser un estorbo formal -el antecedente del exilio- se convertía en una ventaja, en especial a sabiendas de que no estaba solo en el discurso democrático y que las expectativas políticas podían cambiar.

En general, la percepción académica que se tenía en España del concepto de antropología era la que se correspondía con los estudios físico-anatómicos o fisiológicos del hombre. Cuando en mis primeras clases universitarias en Madrid explicaba Antropología Cultural, era frecuente que surgieran preguntas acerca de las diferencias entre la antropología según el modo europeo y la antropología concebida al modo americano. También suscitaba discusión cuando se enmarcaba la antropología filosófica dentro del ámbito del pensamiento, pero no dentro de la epistemología del empirismo. Por otra parte, recuerdo que cuando trataba los pormenores de la antropología social, inmediatamente los estudiantes adquirían posiciones de legitimidad a través de argumentos sociológicos. La perspectiva sociológica era prolífica en la ideación de las sociedades modernas, especialmente en cuanto a la organización y pormenores de la vida social urbana, la propia del Estado. Sin embargo, el papel de los sistemas culturales en la definición de los actos sociales no estaba claro, ya que solía haber una confusión estratégica que resultaba de concebir la actividad sin tener en cuenta los contenidos que la significaban, por lo que en la teoría sociológica, las relaciones sociales se convertían en pauta universal. Los antropólogos usaban como referente en toda teoría antropológica el empirismo etnográfico y lo que cobraba mayor importancia era la especificidad cultural del modo de definir la realidad social.

Mi labor en los dos institutos del CSIC, el americanista y el sociológico, y mi actividad como antropólogo cultural en la Universidad de Madrid definían los límites de la temática en la que solía investigar por entonces. 
Algunos amigos me han preguntado por qué no frecuenté el ambiente del estudio de las tradiciones populares. Debo confesar que por entonces este campo de trabajo lo ocupaban Julio Caro Baroja y Nieves de Hoyos, hija del insigne etnólogo Luis de Hoyos Sainz, y estos nunca me propusieron integrarme en su equipo. En ocasiones, he pensado que quizá fuera debido al volumen de investigaciones que me ocupaban tanto en la universidad como en los mencionados centros del CSIC, pues, probablemente a juicio de aquellos, los consideraban suficientes como para desistir de invitarme.

En todo caso, la universidad y el CSIC me ofrecieron acomodo profesional y los trabajos que allí producía ocupaban el ámbito del americanismo, más concretamente la etnología de América. Al mismo tiempo, además de mi orientación investigadora marcada por las líneas que el sistema formal me ofrecía, en el Instituto Balmes de Sociología pretendía satisfacer algunos intereses personales en el campo de la antropología social mediante una nueva línea investigadora. En la Universidad, el americanismo se entendía más fácilmente desde la perspectiva de la etnología que de la antropología social. Además, mantenía más vínculos con los miembros académicos del americanismo que con los expertos en antropología social, por lo que un mayor acercamiento a esta última disciplina me habría supuesto un sacrificio adicional al tener que esforzarme en ganar nuevos contactos. La amplitud ideológica de quienes trabajaban en el ámbito del americanismo facilitaba mi libertad de maniobra, que era superior a la que por entonces tenían las facultades de política y sociología, por entonces muy endogámicas y exclusivistas.

Un referente importante de mi situación profesional en el ámbito universitario y el del CSIC fue el Congreso Internacional de Americanistas, celebrado en España en 1964. Me benefició enormemente mi condición de americanista, reconocido como tal por parte del grupo español y de otros extranjeros que participaban en su organización y desarrollo. El congreso tuvo tres sedes - Barcelona, Madrid y Sevilla-y a partir de su celebración pude contar con más apoyos, de quienes vinieron de algunos países americanos, como México, Estados Unidos, Argentina y Perú. En este sentido, las autoridades del congreso, Ciriaco Pérez Bustamante, 
Luis Pericot García y Manuel Ballesteros Gaibrois me comunicaron que habían sugerido mi nombre en el Ministerio de Educación para que me nombraran director del Museo Nacional de Etnología, posición por entonces vacante.

La noticia de esta recomendación me llegó indirectamente, por la vía de mi buen amigo, el hispano-mexicano Juan Comas Camps. El cargo no me ilusionaba, aunque era consciente de que podía considerarse importante a efectos de una mayor capacidad de maniobra. Sin embargo, no era precisamente el puesto que pretendía conseguir, pues en concreto pretendía ocupar una plaza fija en la Universidad. Un tiempo después de haberse celebrado el congreso recibí una llamada del arqueólogo y director general de Bellas Artes, Gratiniano Nieto, quien me comunicó que pensaba proponerme para director del Museo Nacional de Etnología, pero pretendía saber antes de hacerlo si estaría dispuesto a aceptarlo. Le pedí unos días para pensarlo y en el ínterin consulté la propuesta que se me hacía con las personas mencionadas. Todas coincidieron en la convicción de que el puesto en el museo era un medio de conseguir prestigio, lo que reforzaría mi posición académica, así que debía aceptar la propuesta cuanto antes.

Así las cosas, tras mi aceptación del nombramiento me hice cargo de la dirección del museo en 1965, aunque no recuerdo con exactitud la fecha. Lo cierto es que cuando tomé posesión y revisé las instalaciones, incluidas sus colecciones etnográficas y la biblioteca, me di cuenta del abandono prácticamente absoluto en que se encontraba. La tarea de reconstrucción que se debía emprender constituía un trabajo mayor del que había esperado realizar.

Para empezar, no contaba con personal técnico. Había un matrimonio que vivía y cuidaba el edificio. El esposo hacía las funciones de portero y, con su esposa, se ocupaban de la entrada y de las visitas del público, por entonces prácticamente una rareza, pues no excedían unas pocas decenas de personas al día. Otro ordenanza que figuraba en la nómina del museo no aparecía para cumplir con sus obligaciones de trabajo. De esta manera, mi trabajo como director era, desde luego, ingente a la vez que desmoralizador. 
Cuando empecé a consultar la biblioteca y a revisar el inventario del museo, la portera me informó de que faltaban muchos objetos, libros, revistas y otras publicaciones. Puesto que no disponía de personal técnico ni de subalternos, aparte del ordenanza desaparecido, invité a tres alumnos de la universidad a que me ayudaran a inventariar objetos etnográficos, además de a reordenar la biblioteca. Bajo mi supervisión comenzaron a trabajar en el inventario. Tras unas semanas, se confirmó que faltaban más de mil objetos etnográficos, así como libros y colecciones de revistas. La portera me comunicó que el ordenanza que no aparecía era el que, probablemente, los tenía en una habitación particular que solía ocupar en el mismo edificio del museo. Cuando lo convoqué, confesó que un director anterior a José Tudela de la Orden y a Julio Caro Baroja había vendido unas decenas de objetos a unos anticuarios de la ciudad. También me informó que las colecciones de revistas, algunos libros y publicaciones diversas las había vendido el mismo director a libreros de la Cuesta de Moyano, lugar en el que habitualmente se mercadeaba con libros antiguos y donde se ofrecían mejores precios.

Esta situación formaba parte del ambiente museográfico del que fui testigo. Aparte de las gestiones que hice para mejorar esta institución, prácticamente enseguida me preocupé por crear nuevos espacios donde ubiqué a algunos investigadores internacionales becados por sus respectivos países para estudiar aspectos de la antropología española. $\mathrm{Mi}$ propósito era crear nuevas funciones, alimentar las relaciones oficiales y académicas del museo y fundar el Centro Iberoamericano de Antropología (CIA), que albergaría la Escuela de Estudios Antropológicos (EEA).

Me ocupé, por lo tanto, de significar el proyecto - esto es, mediante la creación del CIA - entre los universitarios allegados al americanismo. El hecho de que mis acciones tomaran este rumbo en el museo que dirigía me permitía evitar los recelos que se percibían ante la propuesta de hacer lo propio en las instituciones formales, fuera la Universidad o el CSIC.

Por lo tanto, podía impulsar el mencionado proyecto gracias a la capacidad de maniobra con que contaba por mi posición en el museo. De hecho, las personas del sistema universitario a las que consulté, en particular a Ciriaco Pérez Bustamante, Manuel Ballesteros Gaibrois y Luis Pe- 
ricot García, reforzaron con sus opiniones la idea de presentar el proyecto fuera de la Universidad y del CSIC. Esperaba asimismo contar con los apoyos del Instituto de Cultura Hispánica (ICH), precisamente porque su dedicación principal era Iberoamérica. Con este objetivo y, sobre todo, por mi nula capacidad de influencia en el ICH, logré convencer a Ciriaco Pérez Bustamante (don Ciriaco), entonces catedrático de Historia de la Universidad de Madrid y director del Instituto Gonzalo Fernández de Oviedo del CSIC, para que apoyara mi proyecto ante el ICH. La condición que se estableció era que don Ciriaco fuera presidente del CIA, mientras que yo desempeñaría la dirección de la EEA. Cabe añadir que ofrecí los locales e instalaciones del Museo Nacional de Etnología como sede de la escuela y del CIA. El ICH proporcionaría los recursos financieros y, por mi parte, me encargaría de organizar los detalles del funcionamiento de la escuela, además de su relación con el CIA.

De hecho, en esta primera etapa todo fue muy personal. El planteamiento estratégico de la EEA era prioritario, por lo que todo mi esfuerzo se concentró en la idea de lograr su funcionamiento institucional. Mi planteamiento en el ámbito de la antropología era el de Franz Boas, aquel que, recordemos, tomaba en consideración las cuatro ramas y según el que yo había estudiado en la ENAH de México. A este respecto, algunas autoridades de la ENAH, como el doctor Eusebio Dávalos Hurtado, el profesor Wigberto Jiménez Moreno y el doctor Daniel Rubín de la Borbolla me alentaron a realizar el proyecto con ocasión de su visita cuando yo ya desempeñaba el cargo de director del museo. También lo hicieron el doctor Juan Comas Camps y Pedro Bosch-Gimpera, que habían viajado desde México. Por su parte, también lo apoyaron Manuel Ballesteros Gaibrois y Luis Pericot García con visitas a las autoridades del ICH.

La idea también resultaba atractiva para los catedráticos de estudios americanistas con los que consulté sobre mi proyecto. Muchos de estos expertos universitarios defendían la idea de preparar cuadros académicos con estudiantes de países iberoamericanos y estudiantes españoles especializados en el cultivo de las ciencias antropológicas en el sentido boasiano. 
Finalmente, tras ser nombrado director del Museo Nacional de Etnología en 1965 y tras una serie de vicisitudes, pude lograr la creación del CIA, apoyado por el ICH. El argumento básico para su creación se podía justificar teniendo en cuenta que pensaba reunir en la EEA estudios de antropología americanista con los de antropología peninsular. Mi propósito era desarrollar la labor del CIA en función de un acervo cuyo archivo principal estaría constituido por información etnohistórica, básicamente peninsular e iberoamericana. También pretendía formar a antropólogos especializados. Así fue cómo se hizo realidad el proyecto de incorporar un gran centro de investigación al museo en cooperación con el ICH.

El nuevo centro se encontraba en las instalaciones del museo. Así que procuré aprovechar que el personal docente e investigador se encontraba disperso en diferentes facultades de la Universidad española y lo invité a formar parte del centro. El diploma y certificado de estudios que expedía la EEA atestiguaba formación en etnología, arqueología, antropología física y lingüística. Asimismo, un trabajo de campo, realizado en el Alto Aragón, completaba la preparación, también muy marcada por la visión de Franz Boas. Los estudiantes que ingresaron llegaron de las universidades de Madrid, Sevilla y Barcelona, así como contamos con becarios procedentes de diferentes países de Hispanoamérica.

La teoría de los enfoques antropológicos relacionados con el trabajo de campo era de influencia euroamericana y se asemejaba a la visión mexicana en el esfuerzo de abordar temas de investigación relacionados con cuestiones de índole nacional o iberoamericana, temas estudiados en Madrid, mientras que se abordaban otros como la etnicidad, migración, biculturalismo y bilingüismo en Barcelona.

El proyecto hecho realidad tuvo tres años de andadura y quienes allí se formaron se pueden considerar parte de una generación educada en el espíritu boasiano. De hecho, el planteamiento con el que enfoqué la antropología en el EEA emulaba, aunque con menos recursos académicos y económicos, a la realizada por el ENAH en México; de alguna manera, constituía un vínculo de renovación de las relaciones que España tenía con los países de su lengua en América. El desarrollo de la cuestión indígena y los materiales de la antropología entendida como una ciencia apli- 
cada formaban parte del planteamiento del centro. Además, la formación de estudiantes españoles con colegas de países americanos constituía otra de sus características más destacables.

Así las cosas, en 1968 hice oposiciones a la agregaduría de Etnología de la Universidad de Barcelona y obtuve la plaza, lo que me llevó a la disyuntiva de tener que optar entre dos decisiones: una representaba continuar con la dirección de la EEA; la otra consistía en tomar posesión de la agregaduría de Etnología de la Universidad de Barcelona.

Mis amigos de Madrid, sólidos en la amistad, me aconsejaron que me decidiera por ocupar la plaza universitaria de la que me habían nombrado titular. La cuestión no residía tanto en la mayor o menor importancia de los dos puestos, la dirección de la EEA o la agregaduría. Lo que importaba era el hecho de que mi entrada en la Universidad suponía sentar las bases de una estabilidad personal, institucionalmente más protegida, que la que había tenido hasta entonces. Además, corrían rumores de cambios en el ICH y quienes se mencionaban para ocupar sus puestos directivos no me eran favorables en términos de disposición política y de asociación profesional. Estas noticias constituían una buena razón para pensar en sustituciones oportunistas, muy frecuentes en la Administración pública no funcionaria, que podían afectar mi estabilidad en la dirección y planteamiento de los trabajos de la EEA. Por otra parte, la idea de figurar como profesor en la nómina de una institución estatal me atraía más que la de disfrutar de un estatus semejante, en términos de estabilidad y movilidad, en una empresa privada. Mi idea de la función universitaria era la del bien común, mejor definida por el mundo universitario que la incertidumbre que protagonizan los medios del mercado económico. Por otro lado, se estaba iniciando una nueva etapa en la Universidad española a raíz de la entrada de una generación con mayor amplitud de miras. De esta manera, me pareció mejor estrategia integrarme con intelectuales que se gobiernan mejor en función de la idea del bien común, como divisa de sus contribuciones a la sociedad en la que sirven, que con intelectuales que compiten por el bien de su empresa. Dentro de esta perspectiva, una de las dos opciones estaba más acorde con mis convicciones ideológicas. 
También mi experiencia en la ENAH había reforzado mi convicción de que la antropología se correspondía con una clase de conocimiento fundado en la idea de un bien común; o sea, consideraba que, en términos de participación, eran muchos los implicados. La gestión del conocimiento antropológico implicaba a todos quienes tenían la necesidad de conocerse a sí mismos, Administración pública y agentes sociales incluidos.

También tuve en cuenta, por otra parte, que la ENAH, institución pública del Estado mexicano, no me había cobrado matrícula ni gasto alguno y, sin embargo, su eficacia no había sido necesariamente inferior a la de los centros privados que cobraban por estudiar, en el caso, Antropología. A mi juicio, se justificaban más los servicios ofrecidos por el Estado que los sujetos a los negocios.

Una vez dado el paso, fue en consonancia con mis ideales que me dispuse a elaborar mi estabilidad y futuro en la vida universitaria española. Así, me decidí a reiniciar, ahora en el seno de la Universidad, una antropología con el enfoque de Boas, a pesar de que no era en absoluto la perspectiva de la institución española, al igual que ocurría con las del resto de Europa. Enseñar, estudiar y escribir fue mi vocación y la Universidad de Barcelona iba a ser, como había sido la ENAH, un lugar donde cultivarla con la seguridad que otorga la estabilidad laboral.

Permanecí en Madrid cumpliendo compromisos universitarios hasta la finalización del curso 1967-1968. Es menester subrayar que allí hice amigos entrañables, con los que he mantenido lealtad y una relación de iguales, y puedo añadir que me siguieron invitando en muchas ocasiones a participar en simposios, congresos y conferencias. Estos encuentros han sido desde entonces la ocasión para compartir momentos y sentimientos inolvidables, gracias a los contactos necesarios para el desarrollo de proyectos profesionales compartidos.

Habría que subrayar otro hecho: mi actividad social en Madrid se podría considerar un proceso de desexilio. Aunque no hizo de mí alguien diferente por completo, pues mi personalidad no se vio alterada, me cambió el carácter en mi interacción social y transformó los medios con que contaba en mis relaciones con las instituciones. En una sociedad definida por la experiencia social del franquismo, los modos de comunica- 
ción social eran diferentes a los de otros lugares cuando se piensa, por ejemplo, en que todo inicio de relaciones interpersonales obligaba a estar advertido de la ideología y, en su caso, de la militancia del interlocutor. Durante el periodo franquista habían tomado forma lenguajes crípticos de presentación social formal. Por lo que tenían lugar circunstancias de solidaridad espontánea cuando dos o más personas estaban previamente advertidas del modo de pensar de aquellas con las que se iniciaba una conversación. También aprendí a leer entre líneas los mensajes encubiertos de la oposición reprimida. En la vida académica todos los colegas sabían quién era quién y en ella se aprendía a usar ciertos códigos verbales; en las tertulias de café y en los cenáculos amistosos compartidos por quienes se sentían ideológicamente diferentes entre sí, solían observarse diversas convenciones de respeto mutuo que aseguraban la estabilidad y tranquilidad de los discursos.

Cuando se requería discreción, en las conversaciones se evitaban los temas que oponían a las personas. Y en la clandestinidad, la cautela era máxima, como cuando se aprovechaban los actos académicos que reunían a quienes compartían la ideología, pero también se convocaban reuniones en lugares que, se pensaba, ignoraban los agentes que ejercían la represión o que, a priori, no despertaban sospechas de peligrosidad. Este tipo de experiencias fomentaba costumbres y rutinas para controlar individual y socialmente una realidad que se mostraba potencialmente peligrosa.

Desde esta perspectiva, el desexilio consistía en coexistir con una realidad política, la del franquismo, en la que había, por una parte, una diversidad de matices ideológicos entre quienes conformaban la segunda generación, además de los discursos políticos de obediencia institucional homogénea propios de los adeptos al franquismo. Por otra, paralelamente, la débil y fragmentada oposición estaba fraguando sus posturas, que surgían de sus experiencias tácticas. El desexilio no consistía, por lo tanto, en suprimir de la memoria el exilio, sino en crear otra experiencia, la del mundo propio de la realidad social que se vivía todos los días. 


\section{Una antropología periférica: Barcelona}

El 5 de marzo de 1968 conseguí por oposición una plaza de profesor agregado de Etnología en la Universidad de Barcelona. Me incorporé al Departamento de Prehistoria e Historia Antigua, de la Facultad de Filosofía y Letras de dicho centro a partir del curso 1968-1969. En aquel momento la etnología se consideraba subsidiaria de la prehistoria y, dado que los materiales de esta última eran los propios de las culturas primitivas, tuve que adaptar los contenidos al enfoque del plan de estudios del departamento. Así, preparé los materiales de Etnología General, que impartiría desde el enfoque de la teoría antropológica, de la misma manera que Etnología de los Pueblos Primitivos constituiría una descripción etnográfica comparada.

En ambas asignaturas integraba las cuatro ramas, incluso cuando analizábamos datos obtenidos mediante trabajos de campo especializados en una sola. De hecho, aun inmersos mis estudiantes y yo en cuestiones de la prehistoria y de la historia antigua, era fácil discurrir por los meandros de la historia natural. En este sentido, se consideraba la prehistoria parte implícita de la misma historia natural, por lo que impulsé una primera alianza de la etnología con la prehistoria y tomé lo necesario de las ciencias naturales, lo que no menoscababa la visión de la antropología. Al contrario, más bien la complementaba gracias a las variadas aproximaciones y enfoques de los datos obtenidos a través del trabajo de campo. Por lo tanto, no obviábamos la observación clasificada de los fenómenos de la naturaleza y cómo estos influían en las sociedades humanas.

Aunque los geógrafos no acostumbraban a pensar en términos de etnología, lo cierto es que a raíz del trato que tuve con el doctor Joan Vilà Valentí, quien siempre se mostró muy cordial e incluso favorable a establecer una alianza académica entre geógrafos y etnólogos con el objetivo de fundar nuevos proyectos científicos, mi relación con aquellos fue continua. Así, fui testigo de una primera alianza entre prehistoriadores, etnólogos y geógrafos. Huelga decir que, aunque los primeros habían colaborado largamente con los etnólogos y juntos habían sido artífices de conocimientos comunes, la posición de sus respectivos estatus académicos era diferente. En la Universidad de Barcelona, y en la española en 
general, la posición subsidiaria de la etnología respecto de la prehistoria reducía las posibilidades académicas de la primera. Sin embargo, a pesar de su situación, esta constituía una rama que podía emerger con identidad propia y, por lo tanto, elevar su categoría a raíz de su institucionalización.

Evidentemente, la relación de la etnología con la prehistoria hacía patente la necesidad de contar con los enfoques del naturalismo; en realidad, esto era extrapolable a la antropología de manera general. La experiencia académica institucionalizada de la antropología debía entenderse como un estudio físico del hombre. En este sentido, la cultura se entendía como un concepto específico de la etnografía, mientras que el de antropometría se asociaba con la biología. El hecho de que los docentes e investigadores de antropología física estuvieran integrados dentro de la Facultad de Ciencias Biológicas acentuaba la separación facultativa con la etnología. En concreto, la separación de ambas ramas se hacía más evidente tanto en los respectivos planes de estudio, muy disímiles, como en las líneas de investigación, también divergentes. Prueba de ello era el Instituto Fray Bernardino de Sahagún, del CSIC, donde, a pesar de que etnólogos y especialistas en antropología física compartían el espacio, no solo producían materiales de campo diferentes, sino que también investigaban aspectos distintos de la antropología. Ambos grupos de investigadores asistían a los claustros de facultades diferentes, Filosofía y Letras, y Ciencias Biológicas, respectivamente.

En lo fundamental, no había conocido en México una situación semejante a la que me encontré en España respecto a la etnología y la antropología física. Mi experiencia académica al respecto en la Universidad española me convencía de la necesidad de lograr un desarrollo mayor de la primera, no solo por su subordinación respecto a la prehistoria, sino también por su menor peso científico respecto de la antropología física. De hecho, el valor científico de la etnología ya no disfrutaba de convicción académica suficiente; se percibía como si fueran estudios de etnografía exótica.

Mi experiencia académica e investigadora como antropólogo en España distaba mucho del tipo de formación que recibí en la ENAH. Aunque 
en la EEA de Madrid había conseguido reproducir el modelo de estudios conforme a las ideas de la antropología en México, el ordenamiento administrativo de las facultades se había convertido en un obstáculo insalvable. Con todo, por entonces se estaban sucediendo algunos cambios en la Universidad de Barcelona, lo que constituía una cuestión fundamental para poder introducir el modo boasiano de entender la antropología. En el contexto español, estos cambios eran necesarios. En concreto, en la Facultad de Filosofía y Letras estaba tomando forma un proyecto de transformación, definido como Plan Maluquer. Joan Maluquer de Motes y Nicolau era catedrático de Prehistoria y decano de la referida facultad, el impulsor de la iniciativa de modificar el vetusto plan de estudios existente y sustituirlo por otro más identificado con la modernidad que se intentaba introducir en la Universidad de Barcelona.

El claustro universitario estaba viviendo la fuerza de cambio que estaba teniendo lugar en gran parte del ambiente académico y Maluquer era la persona que impulsaba en mayor medida dicha modernización. El proyecto pretendía incrementar el número de asignaturas a la vez que definía una mayor diversidad temática en los programas de estudio. De hecho, incorporaba por primera vez las asignaturas optativas. En lo fundamental, este nuevo criterio permitiría proporcionar a los alumnos una preparación más diversificada mediante asignaturas de otras especialidades académicas. En este sentido, era favorable para los estudios de Antropología porque creaba la posibilidad de recibir clases de otras facultades, en especial la de Ciencias Biológicas, donde se encontraba la mencionada Antropología Física. La opcionalidad permitía mayor flexibilidad formativa y ampliaba el contacto científico de todas las disciplinas. En el caso de la antropología, reforzaba su posición dentro de las ciencias naturales y recuperaba las conexiones interdisciplinarias que se estaban perdiendo en los últimos años, pues como ciencia basada en estudios de campo, además de la etnología, la prehistoria y la lingüística, los cambios facilitaban relacionarla con la antropología física y otras ciencias naturales que se ocupaban del estudio biológico de la evolución humana, lo que daría lugar al desarrollo de planteamientos del evolucionismo cultural. 
Así, mediante la consolidación y desarrollo del Plan Maluquer, podíamos aproximarnos a una antropología concebida de forma mucho más amplia y, por lo tanto, semejante a la del espíritu boasiano. Las asignaturas optativas posibilitaban retomar nexos que estaban cayendo en el olvido en el campo de la antropología cultural, precisamente porque se estaban perdiendo las investigaciones que incluían las ciencias naturales en el estudio de la historia del hombre y de su cultura. El Plan Maluquer favorecía a la vez que los alumnos pudieran cursar asignaturas en otras facultades y reforzaba el desarrollo de algunas disciplinas que se estaban abriendo paso dentro de los programas de innovación universitaria.

Por mi parte, me uní a la comisión que iba a redactar el Plan Maluquer. Formábamos un grupo reducido del que recuerdo los nombres de Joan Bastardas, Pedro Cerezo, Francesc Marsà y algún otro agregado que he olvidado; para la ocasión, el trabajo arduo del plan se nos adjudicaba a los agregados. Los catedráticos apoyaron ampliamente el proyecto, actitud compartida igualmente por los estudiantes, lo que suponía una garantía de apoyo a la implantación del nuevo plan.

Si el espíritu de cambio prevalecía en el ambiente universitario de aquel momento, también es cierto que el Plan Maluquer coincidía con una poderosa manifestación cotidiana de insurgencia estudiantil con respecto a algunas cuestiones de importancia en la política universitaria. Una de ellas pretendía que en el profesorado de la institución académica hubiera más miembros catalanes. En este sentido, uno de los procedimientos del que se servían los catedráticos universitarios era el concurso de traslado. Por este medio, que yo recuerde, catedráticos catalanes de las universidades de Valladolid (M. Palol), Salamanca (J. Maluquer), Valencia (E. Giralt y M. Tarradell) y Murcia, (J. Vilà Valentí) aprovechaban el concurso para regresar a Barcelona. De manera análoga, los catedráticos o los profesores agregados castellanohablantes, como Jaime Delgado, Demetrio Ramos, Carlos Seco, Pedro Cerezo y Emilio Lledó, usaban dicho procedimiento $u$ oposiciones y se dirigían a ejercer a Madrid, Valladolid o Granada.

Los movimientos del profesorado universitario también eran en sí mismos una forma indirecta, ya que no siempre se manifestaba abier- 
tamente, de reaccionar ante cierta conciencia de desarraigo por parte de quienes ejercían en lugares con historia y formas culturales con una identidad que rechazaban, como el caso de Barcelona y sus expresiones catalanistas; también había quienes se regían por prestigio o afecciones, que de todo había a este respecto. Recuerdo, en este contexto, la molestia y desagrado constantes que le producía al personal académico castellanohablante el hecho de vivir un ambiente que volvía a adquirir las señas de identidad catalanas, como estaba ocurriendo en la Universidad de Barcelona mediante la emergencia política de cuadros académicos catalanistas. Esto conllevaba reacciones hacia las nuevas tendencias, así como se generaba de forma encubierta — pues se solían guardar las formascierta hostilidad hacia ellos.

La vuelta de las señas de identidad catalana a la Universidad de Barcelona se manifestaba en conciliábulos de expresión lingüística, de alguna manera, como si se tratara de focos de asociación espontáneos. Se podían observar dos tendencias, la castellanista y la catalanista, cada una de ellas con sus nociones de identificación histórica que daban lugar, respectivamente, a sendos nacionalismos. Se trataba, en definitiva, de una expresión lingüística en la Universidad de Barcelona que reflejaba la identidad reprimida. En este sentido, era frecuente observar incomodidad generada por el uso de la lengua propia tanto en la esfera oficial como fuera de ella. El uso de una u otra lengua estaba cada vez más sujeto a la actitud y a las decisiones personales y este hecho reflejaba la gran potencia simbólica en el juego de las relaciones políticas y del concepto de identidad.

El ambiente en la Universidad de Barcelona era, pues, lingüísticamente militante $y$, en ocasiones, era testigo de incomodidad ante el hecho de que los interlocutores no siempre sabían con certidumbre qué lengua vehicularía una conversación. A priori, se daba por supuesto que el bilingüe -el catalán- cedería por cortesía de anfitrión al monolingüe -el castellano- la prioridad lingüística. Sin embargo, era notorio que en ciertas ocasiones se tuviera en cuenta la antigüedad del castellanohablante en Cataluña para que esta situación generase tensión: el hablante de catalán resistía la voluntad del interlocutor que solo estaba dispuesto a usar el 
castellano a pesar de que, se consideraba, había residido lo suficiente en Cataluña para aprender la lengua.

Estas sutilezas formaban parte del potencial separador de la lengua y, aunque generaban tensiones, por lo común el control social era suficiente para impedir su expresión violenta. En general, el comportamiento en las ocasiones mencionadas del catalán bilingüe y del castellanohablante monolingüe se reducía a episodios concretos y controlados. Sin embargo, ejercían influencia en la toma de conciencia política, relacionada en este caso con la comodidad social vinculada al uso de uno u otro idioma.

Al mismo tiempo, el movimiento estudiantil más agresivo adoptaba la forma de una insurgencia radicalizada en los discursos marxistas de matices libertarios. Desde el punto de vista del profesorado, estos movimientos afectaban la actividad docente, tanto en la apreciación por parte del alumnado de la calidad que pudieran reconocer en el profesor como en la percepción que hacían de la ideología que el profesor introducía en los contenidos, lo que conllevaba la interpretación de las materias impartidas.

Desde esta perspectiva, la radicalización de los movimientos de protesta antifranquista se convirtió en la tónica general de la Universidad de aquellos años, lo que se acompañó de otros nuevos aires. Por una parte, la Universidad se renovaba conforme entraban en ella profesores de orientación más moderna; resultaba relevante constatar la aceptación tácita de jóvenes universitarios formados fuera del país. Como ya apunté anteriormente, se renovaron los programas de todas las disciplinas. El pacto, que podría calificarse de espontáneo, entre los cuadros políticos del movimiento estudiantil y los profesores que participaban en la elaboración del Plan Maluquer intensificó la apertura democrática de la Universidad de Barcelona, algo que también acontecía en el resto de las universidades españolas.

Mientras tanto, tras mi nombramiento como profesor agregado de Etnología, el antiguo catedrático de Prehistoria de la Universidad de Barcelona, D. Luis Pericot García, hombre fuerte en el CSIC de Barcelona, propuso mi nombre para dirigir el Centro de Etnología Peninsular (CEP), puesto por entonces vacante. El CEP estaba adscrito al Instituto Saavedra 
Fajardo, del CSIC de Madrid y, en consecuencia, las decisiones presupuestarias y las relacionadas con los proyectos dependían de la aprobación del instituto. En tal ocasión, propuse como secretario del centro al también etnólogo y director del Museo Etnológico de Barcelona, August Panyella Gómez, quien aceptó la propuesta.

El CEP era una institución sin actividad. Apenas contaba con una oficina en la que había una mesa y dos sillas, y un señor muy amable del que recuerdo su apellido, Vives, que procuraba acudir alguna vez por semana y, según se me comentó, era un erudito sobre folklore musical y conocedor, a su vez, del folklorista Joan Amades, especialista en etnografía de Cataluña. A este respecto, en cuanto tuve conocimiento de que, en algún momento, J. Amades había realizado una encuesta etnográfica en Cataluña y de que esta había desaparecido por completo, pues no había rastro alguno de publicación, inicié mi trabajo en el CEP para averiguar el lugar donde podía estar dicho material. En este asunto, ni Panyella ni yo pudimos conseguir noticia alguna sobre el paradero de la encuesta. Sin embargo, casualmente, mientras me encontraba equipando los locales dentro del edificio del CSIC que servirían para la ampliación del CEP, el profesor Emilio Lledó, catedrático de Filosofía en la Universidad de Barcelona y que disponía en el edificio de un despacho y biblioteca especializada, me avisó de que allí había un armario donde se hallaban unos documentos que, probablemente, podrían interesarme. Se trataba de unos pliegos en cuya primera página se advertía de su contenido y que, con pocas dudas, parecía concernir a la encuesta mencionada. En mi opinión, coincidía con el tema de la encuesta del Ateneo de Madrid que había conducido unos años antes el etnólogo Luis de Hoyos Sainz. El problema de esta documentación era el hecho de que la mayor parte de los pliegos estaban vacíos de información etnográfica. La profesora y doctora Josefina Roma Riu, entonces adjunta a la Agregaduría de Etnología y a quien encargué que ayudara con el trabajo de identificación de los materiales y de su posible ubicación, me comentó que no teníamos indicios del lugar o uso que pudiera haberse dado a dichos documentos. Por esta razón, suspendimos la averiguación, a falta de alguna otra noticia más concreta. 
Con todo, los problemas del CEP se planteaban en términos de déficits. Faltaban equipamientos, una biblioteca, dotaciones para convocar plazas científicas, medidas específicas para formar al personal especializado que formara parte de los proyectos y medios económicos para las diferentes áreas que pensábamos establecer. Ante esta situación, la perspectiva inmediata era disponer de unos locales apropiados para -al menos algunas- de las funciones básicas de un centro científico. La dirección del CSIC de Barcelona proporcionó algunos locales que habían estado vacíos hasta entonces. Asimismo, los amuebló sobriamente y dispuso adelantarnos materiales fungibles a cuenta de un futuro presupuesto. El primer presupuesto que se nos concedió era insuficiente para poner en marcha, por lo menos, uno de los proyectos que habíamos propuesto a la dirección del CSIC de Madrid. El proyecto pretendía adquirir materiales bibliográficos de todos los tiempos relacionados con el estudio general de la etnografía de Cataluña. Tras esta primera fase bibliográfica focalizada en la cultura catalana, también nos planteábamos engrosar los fondos bibliográficos con publicaciones de antropología moderna.

El presupuesto, insuficiente, que no cubría lo necesario para realizar la investigación etnográfica que pensábamos poner en marcha en Cataluña y convencidos, como estábamos, de que las probabilidades de disponer de fondos adecuados para invertirlos en trabajos de campo eran muy escasas, decidimos comenzar por dotar la biblioteca con especial atención a la antropología contemporánea. Asimismo, consideraba conveniente propiciar las condiciones que motivaran a los profesionales de la disciplina. Para ello, como entonces abundaban los antropólogos extranjeros que investigaban sobre etnografía y antropología social en diferentes regiones españolas, pensé que la publicación de una revista de antropología de enfoque boasiano ofrecería un lugar donde distinguir esta clase de estudios de otros que no se ajustasen a la mencionada perspectiva. De esta manera, una parte del presupuesto del CEP se invirtió en la publicación de la revista que, con el nombre de Ethnica, inició en 1971 su recorrido y con la aspiración de convertirse en un medio de difusión internacional de lo que se hacía en España sobre antropología general. 
Mientras tanto, Antropología Cultural, materia que logré justificar e introducir en el nuevo plan de estudios que se había aprobado, había conseguido bastante aceptación entre los alumnos de la Universidad de Barcelona. El éxito del que allí disfrutó impulsó su implantación en otras facultades y universidades, gracias en gran medida al rumbo interdisciplinar que había tomado la Universidad recientemente. Sin embargo, el concepto de etnología continuaba identificándose como parte de la prehistoria, lo que presagiaba un escaso desarrollo estructural de los estudios etnográficos en la Universidad. Es decir, en el contexto de la prehistoria solo se concebía una etnología primitivista, relacionada con los estudios sobre clanes, tribus y sociedades ágrafas. Aunque la relación de la etnología con esta clase de formaciones culturales también formaba parte de sus contenidos, era indispensable ampliar su aplicación a las sociedades complejas. En este punto, mi proyecto personal se dirigía a entender la cultura como concepto fundamental de los estudios antropológicos, por lo que pretendía situarla en un contexto teórico y, a la vez, empíricamente verificable, en el seno de la antropología cultural.

El curso académico de 1969-1970 incluyó por primera vez Historia de la Antropología Cultural. A pesar de que se trataba de una asignatura optativa, su anuncio por parte de la Universidad de Barcelona despertó expectación. De hecho, rompió precedentes de participación y, en consecuencia, se tuvo que habilitar el aula magna de la universidad para dar cabida al volumen de alumnos que se había inscrito, pues el número de alumnos matriculados superaba la capacidad de las aulas de clase de la facultad. Sin duda alguna, la asignatura constituía una novedad en la Universidad española de aquel tiempo. Por mi parte, trataba de ampliar el conocimiento etnológico para aplicarlo a los estudios de prehistoria y lingüística desde una perspectiva específicamente culturalista. $\mathrm{O}$ sea, si se aceptaba que el concepto de cultura era estratégico para explicar antropológicamente los modos de vida humanos, me parecía indudable - y sigue pareciéndomelo- una forma de entender la antropología cultural como punto de encuentro de varias disciplinas antropológicas, como la etnología, arqueología, lingüística y antropología física, esto es, las ramas de la antropología que, con el enfoque de Franz Boas, había estudiado en la ENAH. 
En aquellos años, el marco conceptual y de investigación de los antropólogos se correspondía, bien al ámbito de la cultura, bien al de la biología. Indudablemente, la antropología abarcaba un gran número de disciplinas de las ciencias naturales, pero todas las explicaciones debían integrarse dentro del concepto único de antropología. Se iniciaba en España, por lo tanto, la concepción de la antropología cultural según el marco teórico de las cuatro ramas mencionadas, tres de ellas en la misma facultad, lo que, por otro lado, no era inconveniente para que el estudiante cursara las asignaturas de antropología física en otras facultades.

Conviene asimismo tener en cuenta otras vicisitudes que se produjeron en el momento de poner en marcha el curso de Antropología Cultural, en concreto, en lo concerniente al enfoque del contenido sobre etnología. Mi formación y experiencia en la ENAH, como ya he mencionado, había tomado forma a través de los ámbitos mencionados, las cuatro ramas boasianas. Por lo tanto, era evidente que en la institución mexicana no había recibido formación específica en antropología social, que, en el tiempo en que empecé a impartir Antropología Cultural, estaba ganando adeptos, a pesar de que todavía no había madurado lo suficiente como para ofrecer teorías y enfoques específicos y diferenciados de los de la etnología. Lo cierto es que los contenidos y análisis de la antropología social, en especial por su aproximación a la sociología, eran diferentes de los contenidos relacionados con esta disciplina, que estaban integrados en la etnología.

Recuerdo en este sentido que en la ENAH la aparición de Robert Redfield, que realizó sus estudios de campo en México, había introducido cambios etnográficos ostensibles. El más importante, a mi juicio, era que se concebía marginalizar el detalle etnográfico propio de la etnología, lo que constituía una novedad. Esto es, se tenían muy presentes los datos históricos en las comparaciones entre diferentes grupos geográficamente próximos en la escala evolutiva, como hizo Redfield en su estudio sobre Yucatán, lo que se traducía en una presencia del enfoque etnológico; esto representaba un cambio de visión y, con este, de análisis. De hecho, el estudio de grupos tribales y su comparación con las comunidades indígenas era similar a estudiar, por ejemplo, las unidades sociales de los 
zapotecos o de los mixtecos en sus propios territorios y analizar a sus individuos en la diversidad metropolitana, fuera de sus territorios de origen. Yo mismo había impartido un curso de Antropología Social como parte de la formación de los alumnos del doctorado de Psiquiatría de la UNAM, cuyos contenidos derivaban de estudios de campo realizados en poblaciones rurales y en grupos obreros urbanos.

El contenido de los estudios de antropología social procedía de análisis de las culturas rural y urbana, en ningún caso era totalmente etnográfico. En concreto, constituía la expresión de estudios culturales representados por estratos culturalmente fluidos, es decir, mientras que los individuos agrupados en clases compartían valores trascendentes - por ejemplo, en la esfera religiosa y en la identificación con iconos, como la Virgen de Guadalupe, así como en códigos ideacionales semejantes como los relativos a los sentimientos amorosos-, sin embargo, no coincidían en sus logros sociales para lograr mayor estatus o en la consecución de las comodidades de la escala social. Según el sesgo de la antropología social, los miembros de una comunidad compartían la identidad nacional y las metas económicas, pero en la competición social se frustraban por los desiguales logros individuales, que definían a los individuos en comparación con los otros. Es decir, una misma cultura se podía vivir de modo diferente, según las posibilidades sociales de sus individuos. Pero, con independencia de la clase social, los individuos podían converger en el culto a la Guadalupana, en la idea de una patria común, en el uso de los servicios gubernamentales o en la participación en cualquier manifestación como sociedad.

Ante estas circunstancias, la mayor dificultad residía en darle forma a los contenidos que se impartirían de los tres campos mencionados, la antropología cultural, la antropología social y la etnología, teniendo presentes las diferencias de análisis - $y$, por ende, de aplicación didácticade sus contenidos. No era tampoco una cuestión de arbitraje semántico aplicado al fenómeno de la apreciación histórica de cada valor conceptual. El hecho que se debía considerar era qué concepto interdisciplinar convenía plantearse en términos de alcanzar mayores posibilidades de institucionalización. 
A pesar de que, según la tradición primitivista y preurbana, así como en función del encargo docente, la etnología ocupaba un lugar muy determinado, me pareció más propio construirla dentro de los espacios del concepto de cultura, en gran parte con visión de un futuro desarrollo de esta especialidad de la antropología. En cierto modo, la noción de cultura ofrecía mayores recursos conceptuales para todas las disciplinas ocupadas en el estudio del hombre. O sea, no se restringía a la etnología, lo que, al menos en principio, constituía una especie de representación imperialista del conocimiento: todo lo concerniente a la realización humana le era específico, por lo cual nada debía escapar a la mirada del antropólogo. En este punto, las ciencias naturales le eran propias en lo relativo al empirismo, mientras que las ciencias humanas y sociales no se podían concebir sin la información obtenida a través de la etnografía, gracias a su relación con las ciencias antropológicas.

Estas cuestiones conllevaban también otras consecuencias. Una de ellas era la posible apropiación académica que resultaba de introducir docentes del ámbito de la sociología. Mientras que las propuestas docentes de, por ejemplo, Antropología Cultural provenían de miembros de la misma facultad, las de Antropología Social corrían el riesgo de desplazar los contenidos hacia confusiones críticas con la sociología. En este caso, perdían fuerza la historia, la lingüística y sus vínculos con la etnología. Además del énfasis en la idea de situación, propio de los sociólogos, se corría el peligro de que aparecieran, en lugar de propuestas antropológicas, sociológicas sui géneris en su lugar, lo que podría distorsionar el concepto de antropología hasta desahuciarlo de toda posible implantación estable en un futuro institucionalizado y reconocido por las comunidades académicas que la cultivaban y avalaban. Dado que la sociología en aquel tiempo se ejercía bajo una autoridad ideológica estricta, el traslado de la antropología social a las decisiones de la Facultad de Sociología suponía su sometimiento al control de un ámbito diferente. Así pues, en términos de eficacia y de continuidad, la antropología cultural integraba componentes de la etnología, la prehistoria y la arqueología, la historia —que tomaba forma en la etnohistoria y que en su subdivisión en la historia antigua tomaba la información de las fuentes etnográficas-, la lingüística 
-como la etnolingüística de campo-y hasta la geografía en sus dos vertientes, la física y la humana. Además, a todas ellas podía proporcionarles información sobre situaciones concretas de la organización humana para profundizar en el estudio de la cultura.

Con todo, la antropología social entraba en el discurso de la antropología cultural, siempre en torno al concepto de cultura, estudiado a través de los comportamientos sociales, las relaciones institucionalizadas, de sus individuos. A mi entender, la diferencia de los enfoques de una y otra residía en que el estudio de la antropología cultural ponía de manifiesto las relaciones funcionales entre formas de expresión cultural, las propias de lo superorgánico, según defendían los antropólogos estadounidenses Alfred Kroeber y Leslie A. White. En cambio, la antropología social ponía el foco en las relaciones sociales que, en función de cada cultura, conducían a que los individuos, bien se integraran en las instituciones, bien se mostraran en desacuerdo con estas. Entendía la antropología social, y sigo entendiéndola, como el estudio de las dinámicas sociales que cobran sentido en culturas concretas, en la realización de procesos de socialización y en instituciones como la familia y otras formas de organización de las sociedades humanas, lo que incluye sentimientos y manifestaciones derivadas de la actividad, tanto individual como de grupo.

En realidad, la alianza entre la antropología y la sociología se manifestó de manera evidente a raíz de la impartición de una asignatura de sociología en la facultad, Introducción a la Sociología, y de cuya docencia se me encargó durante el primer año de mi incorporación al claustro de la Facultad de Filosofía y Letras (1968-1969). Se pensaba en su nexo con la etnología, pero sin olvidar los planteamientos empíricos. El tipo de sociología que se estaba enseñando se acercaba más a la filosofía social, aspecto que no merecía crítica alguna, salvo por que no se distinguía claramente entre el positivismo propio del estudio de una ciencia social y la filosofía a secas, es decir, el juicio de la realidad en términos trascendentes. Esta observación esencial diferenciaba la concepción de la sociología de las universidades avanzadas y se oponía a lo que se estaba haciendo en la de Barcelona. En todo caso, había aparecido un sector que abogaba por la modernización de la sociología desde la propia facultad y que no re- 
nunciaba a mantener la asignatura, sino que planteaba la conveniencia de adaptar su enseñanza acorde a la de otros lugares del mundo considerados más avanzados en este aspecto concreto.

El encargo de enseñar sociología tuvo carácter provisional por decisión personal. Aunque no rechazaba la idea de fomentar una visión contemporánea e histórica de entender la sociología en la Facultad de Filosofía y Letras, y que esta materia continuara, estaba decidido a seguir en el empeño de consolidar la antropología en los términos ya mencionados. Con esta iniciativa y apoyado por el doctor J. Maluquer, aproveché la oportunidad para invitar a que se hicieran cargo de Introducción a la Sociología a los profesores Marina Subirats y Jordi Borja, ambos recién llegados de estudiar esta especialidad en París, intelectualmente muy dotados y activos militantes por la modernización universitaria. Fuimos testigos de resistencias por parte de un pequeño sector del grupo docente más tradicional de la facultad, pero pronto se superaron y ambos trajeron nuevos aires a la sociología en la Universidad de Barcelona.

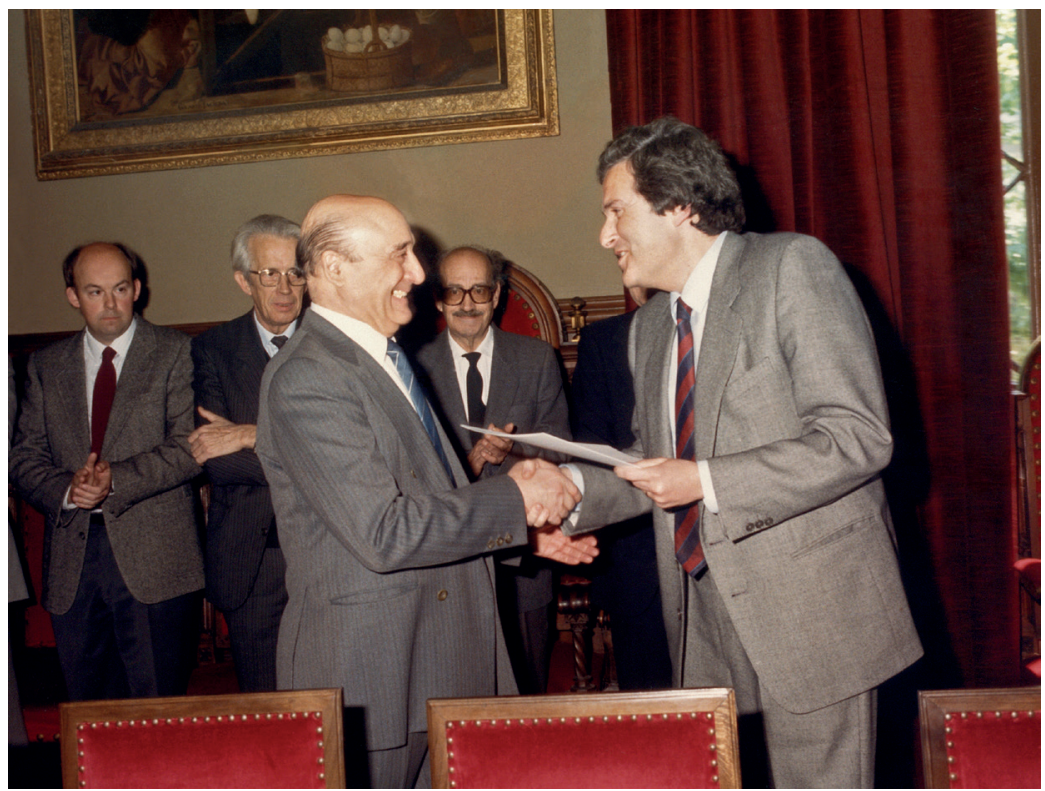

Claudi Esteva Fabregat i el Rector, Josep M. Bricall, Acte d'entrega del nomenament de Professor Emèrit de la Universitat de Barcelona. Barcelona 1987 @ Cortés 
Es fácil concluir, y doy fe de ello, que el proceso de consolidación de la antropología cultural en la Universidad de Barcelona fue difícil, por lo menos en cuanto a la inclusión específica de conceptos y enfoques propios de la etnología. Esto despertaba desconfianzas, no solo por parte de los prehistoriadores, sino también por la de otros grupos académicos de la facultad. A este respecto, con ocasión de analizar la propuesta que hice de introducir Antropología Cultural, se sugirió en su lugar la de Antropología Filosófica. La primera, que yo entendía como una ciencia natural y, por lo tanto, sujeta al empirismo, daba pábulo a que se justificara el empirismo de esta última y la sustituyera en el plan de estudios de Antropología. Es cierto que los reclamos de quienes defendían la asignatura de Antropología Filosófica en lugar de la que yo propuse se fundaban en arraigos académicos muy consolidados, que yo mismo reconocía, ya que la filosofía está presente en toda consideración de la existencia humana. Sin embargo, el hecho de que debiera decidirse entre empirismo y especulación, y obtuviera prioridad el primero, dio lugar a que se clasificara la Antropología Cultural en el campo de las ciencias naturales. Esto consolidaba la firmeza de la investigación de la antropología cultural, por lo cual, hecha la comparación entre las dos visiones, la cultural y la filosófica, y habida cuenta del éxito obtenido por la asignatura de Antropología Cultural, condujo a decidir por esta.

Por mi parte, conforme al propósito de fundar un departamento específico de Antropología Cultural, que ocupaba un lugar destacado en mis preocupaciones académicas, aproveché una oportunidad ofrecida por el Ministerio de Educación y Ciencia. Este ministerio iba a destinar un número de cátedras a la Universidad de Barcelona y, con tal fin, el Departamento de Prehistoria me ofreció que ocupara una en su seno. Ante tal situación, el doctor Maluquer me comunicó la idea de crear una Cátedra de Etnología y pensaba convocarla a concurso de traslado entre los catedráticos con la idea de que la ocupara yo, dado el hecho de que nadie, aparte de mí, era reconocido como titular especialista único de este ámbito y, por lo tanto, nadie más podría ocuparla. No dudé en objetar que se hiciera por concurso de traslado, pues era probable que, a pesar de que yo era el único etnólogo con titulación de la Universidad española, la tra- 
dición favorecía el traslado de catedráticos que, aunque fuera por mera afinidad, pretenderían concurrir al traslado y ocuparse de la etnología sin experiencia y de la cual acabarían siendo unos aficionados. Por esto, propuse al departamento que la propuesta de concurso se cambiara por la de oposición. También propuse que la nueva cátedra no se nombrara de Etnología, sino de Antropología Cultural. Mi objetivo era integrar en el futuro la Agregaduría de Etnología en la Cátedra de Antropología cultural. Tras un pequeño debate, prevaleció mi valoración y se hizo la correspondiente propuesta al rectorado desde el Departamento de Prehistoria, Arqueología e Historia Antigua. Por entonces corría el año de 1971 $y$, realizada la oposición con resolución favorable por parte del tribunal, el 5 de enero de 1972 conseguí el puesto de catedrático de Antropología Cultural. Inmediatamente después hice la propuesta en la facultad para que se constituyera un Departamento de Antropología Cultural. Así, el 28 de octubre de 1972 se obtuvo la respuesta ministerial gracias a la que tomó forma dicho departamento y, al mismo tiempo, se me nombró su director.

No recuerdo exactamente cuándo, pero por entonces se invitó al doctor Sol Tax, de la Universidad de Chicago, a una reunión en Barcelona con el objetivo de incorporar a nuevos miembros en la revista Current Anthropology. En dicha reunión estuvieron presentes el doctor Santiago Alcobé, antropólogo físico, el doctor Luis Pericot, prehistoriador, el doctor Julio Caro Baroja, etnólogo, y el que suscribe, como antropólogo cultural.

El doctor Sol Tax compartió con nosotros lo que se proponía realizar en Current Anthropology y, por nuestra parte, le informamos de nuestros planteamientos y de lo que se hacía en España en antropología. El espíritu imperante en la reunión fue plenamente boasiano, pues todos los presentes coincidimos en asumir que Current Anthropology iba a ser el exponente del enfoque conceptual de Franz Boas. Sin embargo, se reconocieron las dificultades relativas a los obstáculos administrativos y los inconvenientes de superarlos. En este sentido, hice la propuesta de crear un instituto de antropología en la Universidad de Barcelona, donde docencia e investigación se unieran en una institución única y plenamente integrada en el plan de estudios universitario. Como respuesta, se alegó 
la resistencia que ofrecería el marco administrativo y se instó a que se relegara para una futura reunión, hecho que no se produjo finalmente.

En este estado de cosas, el Plan Maluquer se había convertido en el único modo de acceder, indirectamente, a la visión boasiana, pero los acontecimientos posteriores y las medidas urgentes para dar solución a problemas concretos de gestión nublaron el objetivo de especialización directa en cada una de las cuatro ramas. Solo desde el poder de la autoridad política se podía emprender tal fin en un sistema universitario que, afortunadamente, era parcialmente flexible. Así pues, los siguientes pasos se orientaron a integrar plenamente la antropología cultural gracias a las medidas que ofrecía el Plan Maluquer. En este contexto, Antropología Cultural se convirtió en materia troncal dentro del nuevo plan de estudios, lo que facilitó el acceso a la docencia e investigación en esta vertiente de la antropología de algunos alumnos que, a mi juicio, se distinguían del resto.

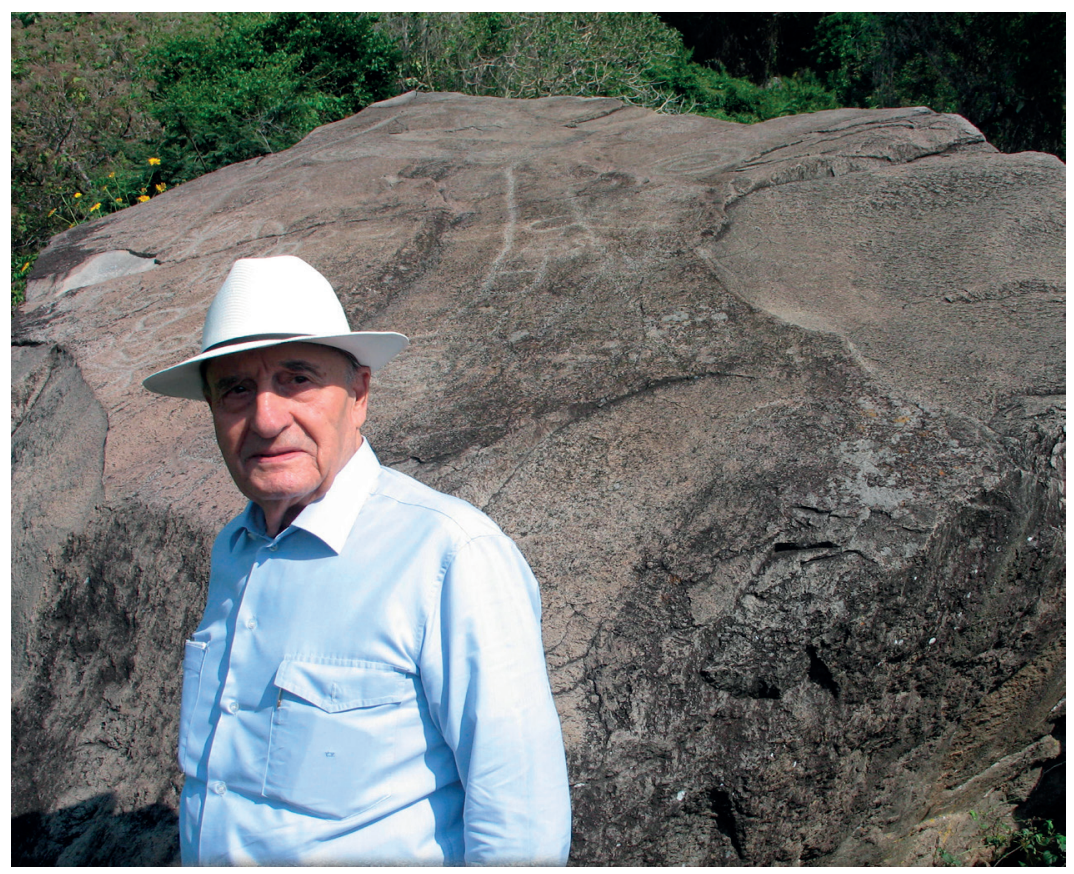

Claudi Esteva Fabregat junt amb glif pròxim a Mezcala de La Asunción, Jalisco, Mèxic 2005 (C) Roberto Pérez Medina 


\section{Epílogo para otra sintaxis}

En el epílogo de lo que he mencionado hasta ahora la sintaxis descriptiva se agota en la gramática de las transiciones. Cada época es fruto de lo que la precede y antesala de lo que está por venir. Y, como no podía ser de otra manera, las experiencias más recientes no solo están menos expuestas a la erosión del tiempo, sino que se enmarcan mejor, se vinculan a otras etapas vitales. Si Madrid representó la vivencia de un proceso de transición y del desexilio, Barcelona es un capítulo que forma parte de otra experiencia, de otra etapa, de tintes periféricos y en la que se estaba construyendo una antropología cultural en un contexto de readquisición institucional de la identidad catalana y de ampliación conceptual de las dedicaciones académicas.

Desde su condición periférica respecto de la de Madrid, desde Barcelona se asume el inicio de otra centralidad, la que se advierte de los usos políticos autónomos y alimentada por el auge de sus seducciones mediterráneas. La sintaxis del logos cultural es diferente en sus medios porque suele fundarse en experiencias de transición, de situaciones biculturales, de bilingüismo, de fuerzas basadas en la etnicidad, de formas constantes de ambigüedad en la corrección de la forma política de la acción, de oblicuidades existenciales que se miden por desconfianzas y por dependencias que obligan a ofrecer apariencias que no son más que máscaras de un ego más sutil que la de su propia superficie cosmética.

Estas líneas son, a fin de cuentas, el relato de una antropología periférica. Solo desde esta perspectiva puede entenderse el proceso de construcción de una antropología cultural. En concreto, la que se iniciaba en Barcelona constituía un modo de construcción institucionalizado y basado, asimismo, en menos recursos de capacidad estructural respecto a los conocimientos que generaba.

Si la elección de «el Claudio» o «el Claudi» manifiesta una toma de posición - que puede variar, incluso mostrarse de manera intermitentedel que lo usa, la historia de la identidad de la antropología cultural en Barcelona tuvo como marca identitaria el hecho de manifestarse en un contexto de periferia, lo que conllevó, en oposición a los organismos que gozan de la condición de centralidad, menores recursos. Fue precisamen- 
te lo que ocurrió con la implantación y primeros pasos de la antropología cultural en Barcelona, lo que, sin duda, hace más valioso el carácter más internacional y de europeidad de este ámbito en el avanzado ambiente universitario de la capital catalana, a pesar de que fuera, a mi juicio, más equívoco en las manifestaciones culturales de la identidad nacional.

El segundo tiempo vital que empezó a tomar forma desde mi llegada a Barcelona, más que reflejar cambios de mi personalidad, era el reflejo de las trasformaciones en las que la memoria es distinta porque lo es la experiencia vivida, perfilada por las realidades a las que uno ha estado expuesto, o sea, las condicionadas por la relación entre la realidad individual y la colectiva. En este sentido, la sinceridad del modo institucional se agota en el discurso de las situaciones coactivas, que es precisamente lo que constituye la experiencia de los caminos que conducían al desexilio, un proceso nunca definitivo porque siempre forma parte de una transición imperfecta.

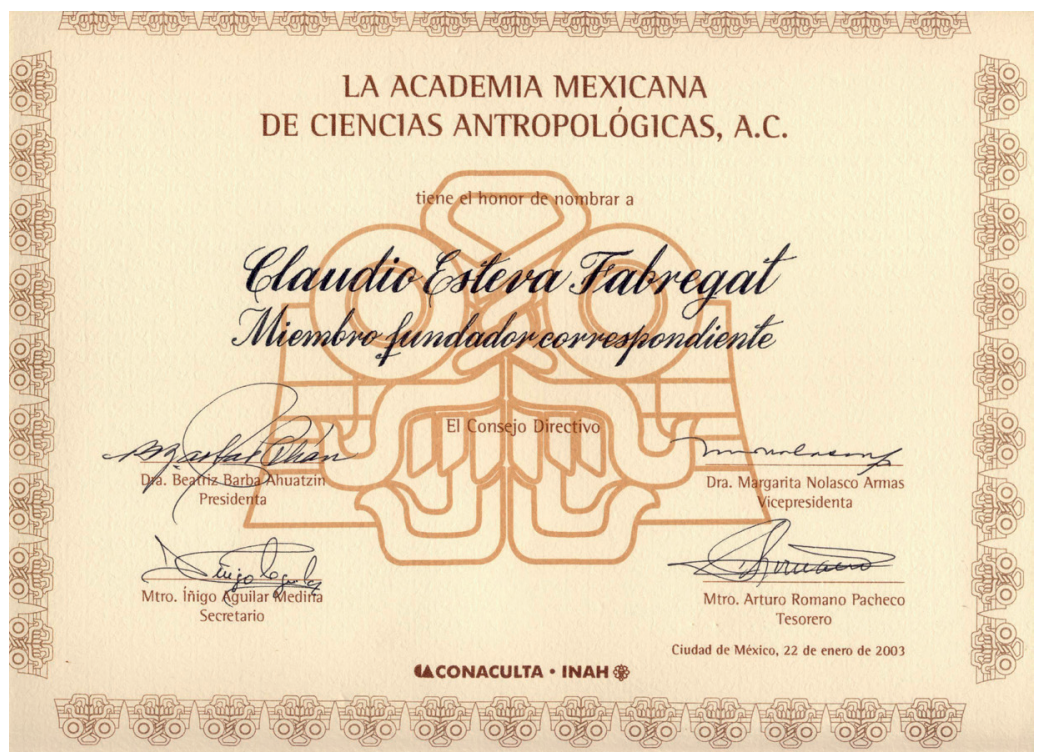

Nomenament de Membre Fundador Corresponent de l'Academia Mexicana de Ciencias Antropológicas, Ciutat de Mèxic, 2003. 


\section{Bibliografía}

CAPEL, H. 2009. «La antropología española y el magisterio de Claudio Esteva Fabregat. Estrategias institucionales y desarrollo intelectual en las disciplinas científicas», Scripta Nova. Revista Electrónica de Geografía y Ciencias Sociales XIII(287). Barcelona: Universidad de Barcelona. Recuperado de <http://www.ub.es/geocrit/sn/sn-287.htm>.

Esteva, C. 1957. «Sobre la teoría y los métodos de la antropología social», Revista Internacional de Sociología 59: 411-436. Madrid: CSIC.

Esteva, C. 2009. «Exilio y desexilio: experiencia de una antropología. México-Madrid-Barcelona», Scripta Nova. Revista Electrónica de Geografía y Ciencias Sociales XIII(291). Barcelona: Universidad de Barcelona. Recuperado de <http://www.ub.es/geocrit/sn/sn-291.htm>. 